\title{
GEOMETRIA DE PERFURAÇĀO EM DRENOS TUBULARES \\ E DESCARGA SUBTERRÂNEA
}

\author{
EDUARDO BARBAT PARFITT
}

Orientador: Prof. Dr. DÉCIO EUGENIO CRUCIANI

Dissertação apresentada à Escola Superior de Agricultura "Luiz de Queiroz", da Universidade de São Paulo, para obtenção do título de Mestre em Irrigação e Drenagem.

\author{
PIRACICABA \\ Estado de São Paulo - Brasil \\ Junho - 1986
}




\section{AGRADECIMENTOS}

- Ao orientador Dr. Décio Eugenio Cruciani pela orientação, incentivo e compreensao.

- Ao Professor Claudio Mancini da F.U.M.S. pelo esforço na colaboração dos trabalhos estatísticos.

- Aos meus irmãos Engos Agrícolas José Maria e Luis Maria Barbat Parfitt pela colaboração nos testes e cuidados es peciais nos meus trabalhos profissionais extra-escolares nas horas dos semetres letivos.

- A Marlene Pereira de Carvalho pelo apoio e colaboração pessoal ao curso em geral. 


\section{ÍND I CE}

Página

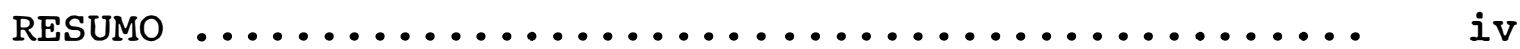

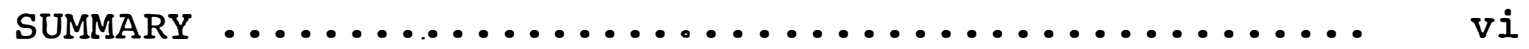

$\begin{array}{ll}\text { 1. INTRODUÇÃO } & 01\end{array}$

2. REVISÃo DE LITERATURA ........................ 04

2.1. Aspectos teóricos ..................... 04

2.2. O problema da Entrada da água em drenos tubu-

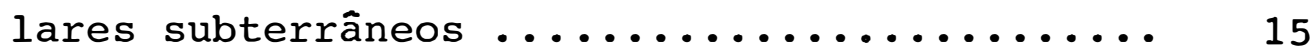

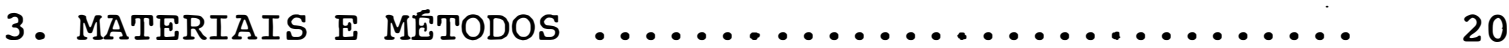

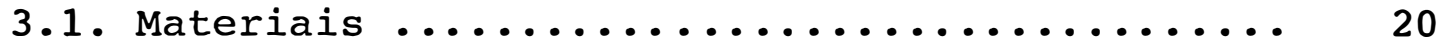

3.2. Métodos ........................... 28

4. RESULTADOS E DISCUSSÃO ................................ 32

4.1. Resultados dos testes preliminares sem Bidim. 32

4.2. Medidas de descarga do dreno com envelope de Bidim e carga hidráulixa constante ........ 35

4.3. As medições do dreno com envelope de Bidim no solo Arenoso e Solo Latossolo Vermemlho Areno

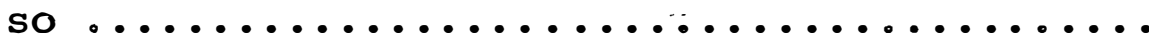

5. CONCLUSÃO ........................... 


\title{
GEOMETRIA DE PERFURAÇÃo EM DRENOS TUBULARES E SUA DESCARGA SUBTERRANEA
}

\author{
Candidato : Eduardo Barbat Parfitt \\ Orientador : Prof. Dr. Décio Eugenio Cruciani
}

\section{RESUMO}

o experimento foi montado em quatro caixas de alvenaria preenchidas com solo e contendo um dreno tubular de PVC rígido de $100 \mathrm{~mm}$ de diâmetro com 36 a 72 perfurações circulares de $1 / 2$ polegada de diâmetro dispostas em quatro e oito linhas diametralmente opostas.

o solo foi saturado com água para melhor homoge neização visando obter condições de igualdade estrutural entre as caixas. O nivel freático foi mantido permanentemente em nível constante acima da superfície do solo durante todo o período das medições de descargas.

A entrada de água nas caixas se dava por uma re de de tubos de $3 / 4$ polegadas perfurados e dispostos junto ao fundo para produzir um lençol freático e saturação completa 
do solo. No momento da medição das descargas a entrada de água nas caixas se dava pela parte superior para facilitar a manutenção da carga constante.

A descarga dos drenos era medida coletando volu mes com provetas graduadas em ml durante intervalos de tempo constantes.

Todos os orificios foram obstruídos por " rolhas de borracha que manualmente, pelo interior do tubo, eram reti radas progressivamente para medir a descarga individual ou em grupos.

A descarga do dreno era sempre livre, isto é, não foi produzida uma lâmina significativa que atuasse como carga hidráulica contrária à carga hidráulica do nível freátị co.

Assim sendo, as condições" de contorno do sistema, eram mantidas constantes variando apenas a carga hidráuli ca efetiva sobre o dreno e o número de orifícios abertos.

o experimento teve um teste inicial em água pura.

Posteriormente foram testados dois tipos de so10: areia e um latosol. 
-vi.

\title{
THE GEOMETRY OF SUBSURFACE DRAIN OPENINGS ON THEIR DISCHANGE
}

\author{
Author : Eduardo Barbat Parfitt \\ Adviser : Prof. Dr. Décio Eugenio Cruciani
}

\section{SUMMARY}

The experiment was conducted in four brick lysimeters filled with soil and provided with a rigid PVC Drain tube with $100 \mathrm{~mm}$ inside diameter, with 36 to 72 circular $1 / 2$ inch openings distributed through four and eight rows simmetrically.

The soil was saturated with water for better homogeneity and compaction in order to achieve equal structural conditions among the replications.

A constant ponded water layer was kept over the soil surface during the measurements of discharge.

Input of water for saturation of the soil was induced through $3 / 4$ inches perforated PVC pipe network installed at the bottom of the lysimeters. 
Discharge was measured collecting volumes at constat time intervals.

The openings in drain were closed with rubber stoppers that were removed progressively by hand to measure discharge in single or multiple openings.

The flow from drains was always free of countepressure relative to the hydraulic head on the drains.

In this way the boundary conditions of the system were constant during each set of measurments except for the effective hydraulic head or water table and for the number for openings flushing at each time.

The experiment was first set with water only, then two soils were tested one sandy one clay soil. 


\section{-1. INTRODUçÃo}

Sistemas de drenagem bem projetados são de im portância fundamental para aumentar e melhorar a produção agrícola, seja em regiões úmidas, como naquelas irrigadas on de, por vários motivos, existe uma drenagem natural deficien te. O que se exige desses sistemas è que exerçam um controle efetivo da água do solo antes que a produção da cuḷtura seja prejudicada.

Nas regiões irrigadas a salinidade pela eleva ção do nível fréatico tem afetado a produção, causados pela má qualidade da água, pelo manejo errado do sistema solo-água e pela falta de drenagem adequada.

Os conhecimentos teórico-práticos atuais sobre os múltiplos aspectos que envolvem um problema de drenagem na sua avaliação e nas soluções mais indicadas, são bastante satisfatórios e completos. Entretanto, ainda subsistem dúvidas quanto a alguns problemas específicos, especialmente 
em nosso País, como por exemplo a tolerância de várias cultụ ras ao excesso de água no solo em função de sua produção e quanto ao desempenho de drenos, entre outros.

A necessidade de uma infraestrutura de base para apoiar e desenvolver a drenagem é marcante. Temos carên cia de máquinas para drenagem, materiais de drenagem e de informações seguras quanto ao desempenho desejável desses mate riais para os nossos solos.

o PROVARZEAS é um programa nacional que tenta recuperar o atraso nessa área, mas suas metas de expansão agrícolas necessitam de apoio de pesquisa básica desenvolvida em nossas condições, sem extrapolações do exterior, sempre duvidosas quanto a sua validade no Brasil.

Dentro desse enfoque são importantes as contribuições que possam trazer mais luz quanto ao desempenho de diferentes tipos de drenos especialmente os drenos tubula res subterrãneos que estão sendo cada vez mais utilizados no mundo inteiro.

A literatura em geral enfatiza a necessidade de mais informações quanto ao seu desempenho em condições mais variadas. Um desses pontos de dúvida que tem merecido mais atenção pelos pesquisadores é a geometria das perfurações desses drenos tubulares. Muito pouco tem sido estudado e publicado. 
Tanto é verdade que todas as equações de cálculo do espaçamento de drenos mostram, por exemplo, que ele è proporcional à condutividade hidráulica do solo e inversamente proporcional à taxa de descarga exigida dos drenos, mas não fazem menção ao tipo e número de perfurações ou orifícios que o tubo deve ter. Isso significa que nos cálculos os drenos são supostos totalmente porosos ou sem resistência a entrada do fluxo de água.

Assim sendo, o propósito deste trabalho foi procurar observar e quantificar o efeito do número e da posi ção dos orifícios circulares na descarga de drenos tubulares de PVC envoltos com um envolope uniforme sintético denominado comercialmente de Bidin, em dois tipos de solos. 


\section{REVISÃO DE LITERATURA}

\subsection{Aspectos téoricos}

- fluxo de água subterrānea em direção aos drenos é condicionado por diferentes fatores e nesse proces so, as condições de contorno do sistema podem ou não permanecer invariāveis (Figura 1). Assim, quando os limites do sistema não se alteram, condição que ocorre quando a recar-

ga do solo (R) é igualada pela descarga dos drenos (q), o nível freático (NF) permanece estático. Essa ē uma condição raramente encontrada no campo, especialmente em nossas condições climáticas. Essa situação é conhecida como de … Fluxo Permanente ou condição de equilíbrio (STEADY ... STATE FLOW), CRUCIANI \& BOTREL (1986).

A grandeza de fluxo subterrāneo depende da recarga do solo $\mathrm{R}$, da geometria do perfil, da porosidade 


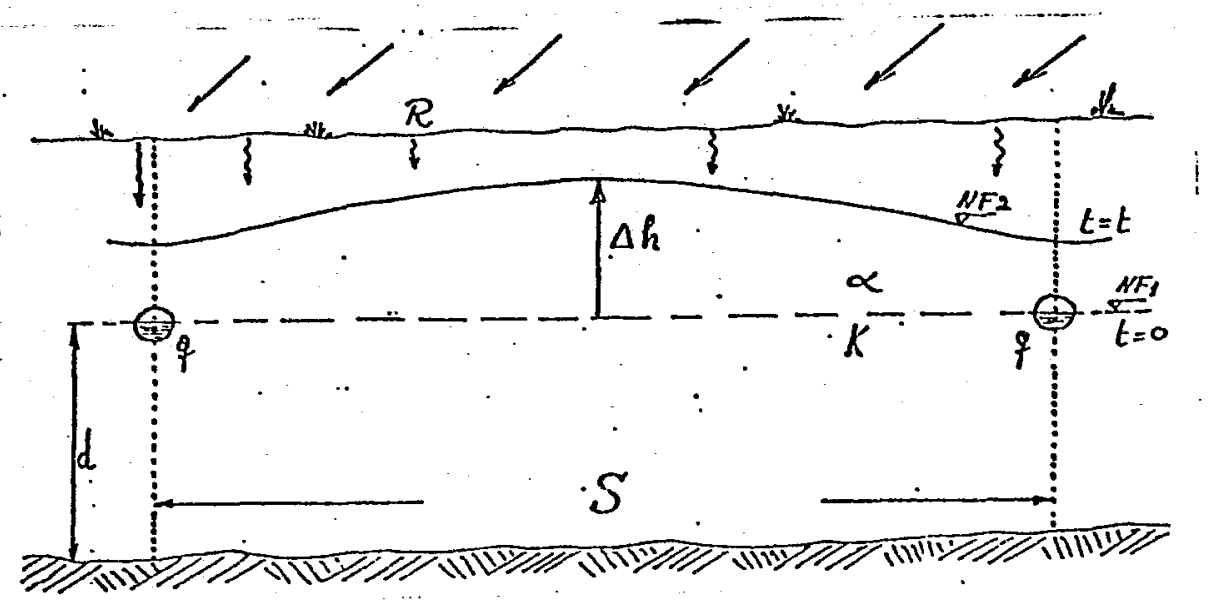

Figura 1 - Contornos de um sistema de drenagem

drenável do solo $\alpha$, de sua condutividade hidráulica saturada $K$, do espaçamento dos drenos $S$, e do gradiente hidráulico $i=\mathrm{dh} / \mathrm{dx}$ induzido pela presença e dimensão dos drenos.

Em condições de fluxo não permanente ou de não equilíbrio (NOSTEADY ou TRANSIENT FLOW) a recarga não é igualada pela capacidade de descarga dos drenos. Em consequência, mantendo o espaçamento dos drenos o único contorno. variável do sistema que é o NF acaba sofrendo uma elevação $h$ no perfil em decorrência da recarga do solo. Essa alteração do NF, ocorre apesar da ação de descarga produzida pelos drenos, especialmente quando a recarga se processa em tempo não muito prolongado e principalmente quando seu valor é intenso, como ocorre em nossas condições segundo CRUCIANI O BOTREL (1986).

Entre as várias equações disponiveis atualmente para o cálculo do espaçamento de drenos, pode 
ser destacadas para condições de Steady state a equação de Hooghodt, também conhecida como equação de elipse:

$$
S^{2}=\frac{4 k\left(b^{2}+2 b d\right)}{q}
$$

e também a equação de Kirkham

$$
\begin{gathered}
S=\frac{K \cdot b}{q} \times \frac{1}{F} \\
\text { sendo } F=1 / \pi \mid \log \frac{S}{\pi r}+\sum_{n=1}^{\infty}\left(1 / n\left(\cos \frac{2 n r}{S}-\cos n\right) \cdot\left(\operatorname{cotgb} \frac{2 n \cdot d-1)}{S}\right)\right.
\end{gathered}
$$

Quando ocorrem situações de fluxo não permanente (Nonsteady Flow) mais real em nossas condições de cam po, as equações disponíveis são menos numerosas, destacando se a equação de Glover-Dumm:

$$
S^{2}=\frac{I^{2} \cdot \mathrm{K} \cdot \mathrm{d} \cdot \mathrm{t}}{\alpha \ln \left(1,16 \mathrm{~h}_{\mathrm{o}} / \mathrm{ht}\right.}
$$

Como se vê ha contraste entre equações mais simples e as de forma complexa sem contudo haver referência a possiveis limitações hidrăulicas dos drenos encarregados de controlar a água no perfil do solo dentro de um tempo li mitado em função das recargas esperadas. Os drenos são supos tamente de máxima eficiência hidráulica e sem resistência de entrada para que as equações funcionem na prática, LUTHIN (1973), SCHILFGAARDE (1974), CRUCIANI (1986).

KIRKHAM (1950), estudando o fluxo em direção a drenos paralelos em solo saturado e mediante a determina- 
ção da rede de fluxo no plano bidimensional (perfil do solo) estabeleceu que o fluxo de entrada num areno é dado por:

$$
Q=\frac{2 \pi K(d+h-r)}{\log (2 h / r)}
$$

sendo: $Q=$ fluxo de entrada por unidade de comprimento de dreno e por unidade de tempo

$\mathrm{K}=$ condutividade hidráulica do solo

d = lâmina de água acima da superfície do solo

$\mathrm{h}=$ profundidade da superfície do solo até o centro do tubo

$r=$ raio externo do dreno (que inclui o envelope).

Em seu experimento verificou que o fluxo de entrada é proporcional à profundidade do dreno num solo homogêneo e que é apenas levemente afetado pelo diâmetro do dreno. As conclusões mais importantes dessa análise é que a equạão não inclui o efeito das aberturas ou perfurações no dreno, isto é, essa equação supõe um dreno totalmente aberto (ou totalmente poroso).

A mesma análise é feita por KIRKHAM \& SCHWAB (1951), estudando o efeito da descarga nas perfurações circulares em drenos tubulares. Chegaram a conclusão prática que a vazão $\left(Q_{S}\right)$ por unidade de comprimento e por unidade de tempo é: 


$$
Q_{S}=\frac{2 \pi K(d+t-r)}{c+\log (2 h / r)}
$$

sendo C uma constante que envolve a geometria do dreno e as propriedades físicas do solo. As conclusões mais importantes dos trabalhos (parte I e II) dos mesmos autores são: a) o dreno perfurado envolto por um envelope tem o fluxo de en trada significativamente maior do que sem o envelope; b) pa ra uma densidade de 4 furos por pé de comprimento do tubo, - fluxo é diretamente proporcional à densidade de perfurações; c) acima de 4 furos por pé de comprimento do tubo o aumento de fluxo não é proporcional ao aumento dé número de furos embora seja maior; d) dobrando o número de furos não dobra o fluxo de entrada, embora ele aumente subs tancialmente.

KIRKHAM E SCHWAB (1951) e SCHWAB (1955) estudando o efeito das perfurações no fluxo de entrada de água em drenos tubulares observaram que com o aumento do número de orificios no tubo o aumento relativo do fluxo de água di minui, particularmente se existem mais de 20 furos por pé de comprimento do tubo. Por outro lado, dobrando o diâmetro das perfurações de $1 / 4$ para $1 / 2$ de polegada a uma profundi-. dade de 4 pés da superfície do solo o fluxo de descarga aumentou respectivamente de 68 e $46 \%$ para 4 e 10 furos. 0 efeito das perfurações na redução do fluxo (efeito inverso) é menor quando o dreno está mais profundo do que quando mais próximo da superfície, o que mostra claramente a desvantagem de drenos muito superficiais. 
Finalmente, concluem os mencionados autores, que o uso de envelope envolvendo tubos perfurados implica na necessidade de menor número de perfurações para obter um fluxo de descarga desejado.

JONES (1960) encontrou que o máximo espaçamen to das juntas entre tubos não perfurados, para evitar entra da de sedimentos, deveria ser de $1 / 16$ polegadas para solo barro limoso e $1 / 8$ polegada para solo barro argilo-linoso. A submergência de saída (areno afogado) aumentou a entrada de sedimentos de 30 até $100 \%$, que segundo ele, deve ser um fator a ser considerado para estabelecer o tamanho $\because$ ideal das juntas.

YOUNG (1965) verificou que o fluxo de entrada através de juntas mantidas livres de areia foi três vezes maior do que com juntas em contato com areia. Encontrou, ainda, que o fluxo relativo, em tubo de plástico com abertu ras na forma de fendas, em comparação com um dreno aberto era de $25 \%$ em comparação ao trabalho de KIRKHAM (1950), que era de $21 \%$

DE BOER E JOHNSON (1965) estudaram o efeito das juntas e perfurações em condições de campo, com sistemas de saída por bombeamento. Eles concluiram que não houve diferença significativa entre as descargas de drenos com ma nilha com juntas variando de $1 / 32$ até $3 / 8$ de polegadas. 
E possivel que as leituras feitas em relação ao período de bobeamento na saída tenha influenciado os resultados do trabalho dos mencionados autores.

SCHWAB, FREVERT, EDMINSTER e BARNES (1966) em

seu livro Soil and Conversation Engeneering, descrevem em Teoria da Drenagem Subterrânea, que o fluxo de água para os drenos é influenciado por diferentes fatores, ou seja, permeabilidade do solo, profundidade dos drenos, abertura nos drenos, distribuição do potencial hidráulico no solo, espaçamento dos drenos e diâmentro dos mesmos.

Ao fazer uma análise teórica para rebaixamento do lençol freático duas condições básicas devem ser verí ficadas, ou seja, condições de fluxo permanente (Steady-Stą te) e condições de fluxo não permanente (non Steady-State). Uma sintese dessa análise que apresenta as equações mais utilizadas no cálculo do espaçamento de drenos, respectivamente para essas duas condições de fluxo de áqua no solo es tá descrita no trabalho de CRUCIANI e BOTREL (1986).

WESSELING e HOMMA (1967) mediram a resistência de entrada da água em arenos de plástico com diferentes números de aberturas longituainais nas paredes do tubo e com diferentes tipos de filtros em tanques de areia. Verificaram que aparentemente a influência do aumento do número de perfurações na redução da resistência de entrada da água, 
tinha um limite e que se reduzia quando a densidade de perfurações se elevava. Segundo esses autores, para reduzir a resistência de entrada é mais eficiente aumentar o diâmetro do dreno do que o número de orifícios.

LUTHIN et alii (1968) estudaram os fatores que afetam o gradiente hidráulico de saída na interface solodreno e que afeta, portanto, a entrada de água no dreno. Por isso a equação do cálculo de espaçamento de arenos proposta por KIRKHAM e LUTHIN (1957) foi programada para solução em computador na qual se procura obter o fluxo de uma série de drenos paralelos tubulares em função de sua profun didade e distância da camada de impedinento e do diâmetro do dreno. No seu tratamento teórico assume-se o solo homogêe neo e que os drenos descarregam a plena seção.

Ainda, os resultados das análises que incluiram um tratamento com envelope, indicaram a existência de um gradiente hidráulico da saída na interface do solo, supe rior ao gradiente critico tolerado para areia. o gradiente hidráulico na interface solo-dreno: aumentou com a diminuição do diâmetro do tubo e, por outro lado, o mesmo gradiente diminuiu quando odreno estava mais próximo da barreira impermeável.

Nesse trabalho LUTHIN et alii (1968) não investigam o efeito do espaçamento dos orifícios no dreno que foram considerados completamente permeáveis. 
SCHWAB, DE BOER \& JOHNSON (1969) estudaram O efeito das perfurações no dimensionamento dos drenos tubula res subterrâneos através das medidas de descarga e rebaixamento do lençol freático num sistema de drenos subterrâneos paralelos. De maneira geral, o efeito das perfurações, segundo eles, não têm sido considerados na maioria das equações de fluxo ou nas fórmulas de espaçamento.

De maneira geral, os experimentos mostraram que as dimensões das perfurações circulares, retangulares e outras, são limitadas basicamente pelo problema de entrada de sedimentos, mais do que pelo problema do fluxo de entrada de água. Entre esses trabaḷhos estão WATTS e LUTHIN(1963) e KIRKHAM (1950).

GLENN et alii (1969), seguindo a mesma linha de estudos concluem que o espaçamento das perfurações em drenos tubulares tem pequeno efeito no fluxo de entrada quando a relação entre o menor para o maior espaçamento de furos é maior que 0,2. Recomendam um espaçamento de furos. uniformes.

Por outro lado, um aumento desejado no fluxo pode ser obtido aumentando o número de perfurações ou espacamentos entre juntas em trechos curtos de dreno. o efeito do maior adensamento das perfurações no rebaixamento do len çol freático é maior quando diminue o espaçamento dos drenos e a porosidade do solo. 
GULATI et alii (1970) realizaram um trabalho com a finalidade de encontrar meios para o controle da entrada de sedimentos em arenos subterräneos, dando ênfase a esse problema que tende a diminuir grandemente a eficiência e vida útil dos drenos. Entre os mecanismos de redução do problema que ocorre em solos não corrosivos destacam uso de envelope, diâmetro grande aumento do declive do dreno, dimi nuição das juntas e localização das perfurações na metade inferior do dreno.

A ênfase de seu trabalho foi verificar median te modelos matemáticos e de analogia elétrica, para simular a rede de fluxo e determinar a velocidade crítica para sedimentação de partículas nos drenos, como a velocidade critica para o solo não coesivo na interface solo-dreno.

Os fatores que influenciam o fluxo de entrada em drenos tubulares foram estudados por LUTHIN e HAIG(1972) em condições de laboratório utilizando tanques de solo e areia onde foram comparados resultados experimentais com da dos teóricos. Eles concluiram que dobrando o diâmetro do dreno de 2 para 4 polegadas a descarga dos drenos foi de 35 a $60 \%$ dependendo da altura do nível freático acima do dreno. Diminuindo o comprimento dos tubos de 3 para 1 pé 0 fluxo de entrada de 2 a 25 vezes através do maior número de juntas. Entretanto, envolvendo os tubos com envelope com fibra de 
vidro o efeito anterior foi reduzido passando a ter incremen to de apenas $50 \%$.

Observaram ainda, que as taxas de descarga dos drenos eram maiores quando nos tubos perfurados os orifícios estavam localizados na base do mesmo devido a maior carga hi dráulica inicial. Entretanto, com o escoamento mantendo uma lâmina de água no interior do tubo reduz-se a carga hidráuli ca efetiva reduzindo a vantagem da posição do furo na parte inferior.

Ainda, mantendo as condições de contorno do sistema invariáveis, notaram um rebaixamento linear proporcional e mais rápido, com o aumento do diâmetro do dreno. Is to está de acordo com a teoria de Dupuit-Fordchheimer que as sume que a descarga dos drenos está diretamente relacionada com a altura do nî̀vel freático na parte central entre dois arenos. 


\subsection{O Problema da Entrada de Água em Drenos Tubulares Subterrâneos}

IUTHIN (1973), tratando desse problema, mencio na que no caso de drenos subterrāneos a āgua deve entrar através das juntas de tubo sucessivas ou através de orificios em tubos perfurados. Alguns tubos porosos têm sido testados, mas a entrada de água nesses casos tem sido desprezível. Quando se usam drenos "Toupeira" feitos com torpedo em solo muito argiloso a água entra nessa galeria por infiltracão através de todo o perímetro bem como pelas fendas produzidas nos horizontes superiores do solo. Algumas análises indicam que dobrando a largura da fenda deixada entre juntas sucessivas de manilhas não perfuradas, aumentou a entrada do dreno em aproximadamente $10 \%$ sob condições. de nível freático alto e estável.

Se o dreno é envolvido por um material poroso de proteção denominado de "envelope", segundo o mencionado autor, o dreno atua como se fosse permeável em toda a extensão quando a permeabilidade do envelope é bem maior que a permeabilidade do solo.

Outros testes revelaram que tubos de concreto em segmentos de 30 polegadas, com envelope, permitiram um fluxo de entrada, através das juntas, igual ao de tubos com 12 polegadas de comprido sem envelope. 
Quando o solo é estável, o mesmo autor recomen da juntas entre manilhas de $1 / 4$ a $1 / 8$ polegadas. Quando $\circ$ so lo é instável, como por exemplo com muita areia fina, essas juntas devem ser as menores possiveis.

Ainda, segundo LUTHIN (1973), o fluxo de água para os drenos subterrâneos é grandemente influenciado pelas condições hidrāulicas imediatamente vizinhas ao dreno. maior perda de carga hidráulica ocorre exatamente nas vizinhanças do dreno, daí a importância do efeito do envelope nesse fluxo de entrada. Isso é fundamental, pois esse fluxo governa diretamente o rebaixamento do lençol freático no per fil do solo.

BRAVO e SCHWAB (1975), estudaram o efeito das aberturas em drenos de plástico e corrugados sob influência da presença de solo entre corrugações em condições de solo homogêneo, isotrópico e saturado. Os seus estudos envolvem modelos de analogia elétrica para esmar as condições reais no solo (modelos matemáticos).

Os resultados foram relacionados a um dreno pa drão cilindrico de $114 \mathrm{~mm}$, de diâmetro externo perfeitamente atribuindo para ele um fluxo nominal de $100 \%$. O modelo do mesmo diâmetro corrugado, com orificios circulares de $8 \mathrm{~mm}$ è espaçados de $35 \mathrm{~mm}$ produziu um fluxo relativo de $80 \%$. O modelo de dreno comercial padrão, com aberturas em fendas e de 
diâmetro de $114 \mathrm{~mm}$, com solo entre as corrugações, produziu um fluxo de entrada relativo de $44 \%$ em relação aos anteriores. Quando havia solo nas corrugações e nos orifícios o flu u xo relativo foi de $39 \%$ em relạ̧ão ao padrão. Essas condições de solo se referem sempre à parte interna do tubo.

SOMMERFELDT (1975), testou o desempenho de dre nos tubulares de plástico corrugado de 55,65 e $105 \mathrm{~mm}$ de diâa metro interno e com diferentes tipos de perfuração e, tubos de cerâmica (manilhas) de $105 \mathrm{~mm}$ de diâmetro interno com jun tas espaçadas. Os materiais usados foram envolvidos com enve lopes de cascalho e fibra de vidro. Dois tipos de solos foram estudados: barro arenoso cada um dos quais tinha sido ho mogeneizado e pulverizado em caixas (lisimetros de $0,75 \times 0,7 \underline{5}$ x 1,20m de comprimento). O nível freático foi mantido constante a $5 \mathrm{~cm}$ acima da superfície dos: solos. Os drenos foram instalados a $15 \mathrm{~cm}$ do fundo das caixas. As variáveis do traba lho foram: o tipo de dreno, tipo de perfuração, grandeza dos orificios e das juntas e dois tipos de solo. o experimento se prolongou a intervalos durante dois anos. De maneira geral nenhum dreno se destacou dos demais quanto às descargas produzidas.

Nos lisimetros, segundo o mesmo trabalho, com envelope de cascalho, a descarga do dreno de 55m de PVC rígido foi comparável ao da manilha, porém, quando sem envelope, foi substancialmente inferior ao da manilha. A descarga 
inicial no tubo de PVC de $65 \mathrm{~mm}$ sempre era maior que na mani1ha, mas com o passar do tempo, havia uma inversão desses va lores. A descarga no dreno de plástico flexivel com $105 \mathrm{~mm}$ va riava entre aquele do dreno de $65 \mathrm{~mm}$ e a da manilha de $105 \mathrm{~mm}$ aproximando-se com o tempo desta última.

Foi observado ainda, pelo mesmo autor, que no solo barro arenoso, sem envelope, a descarga nos drenos de plástico de $65 \mathrm{~mm}$ e de $105 \mathrm{~mm}$ era o dobro da vazão da manilha.

Para efeitos práticos, segundo o mesmo autor, um tubo de $4 \mathrm{~cm}$ de diâmetro, com uma manta de fibra de vidro necessita de $450 \mathrm{~cm}^{2}$ de perfurações por metro linear. Contudó, com arenos com essa geometria dificilmente se consegue reduzir mais a resistência de entrada. Somente quando a permeabilidade do solo no preenchimento da valeta é muita baixa $(10 \mathrm{~cm} / \mathrm{dia})$. Nesses casos é preferível aumentar o envelope ou - um diâmetro maior.

Encontrou ainda o mesmo autor que para condições práticas de campo existe uma relação entre a resistência de entrada $W_{e}$ e a permeabilidade do solo $K$ que em papel Di-log è linear:

$\mathrm{w}_{\mathrm{e}}=\mathrm{a} \mathrm{K}^{-\mathrm{b}}$ com valores do coeficiente angular de $-0,9$ a $-1,1$ (em média -1). Para os valores de (a) foram encontrados de 0,066 (tubo todo permeável) até 0,150 para duas linhas de furos por metro linear $\left(450 \mathrm{~cm}^{2}\right)$, isto é para 
a geometria básica descrita acima. A conclusão final é que para a Holanda esse dreno é satisfatório na maioria dos casos. SKAGGS (1978) afirma que os métodos convencionais de previsão do rebaixamento do nível freático no solo sob efeito da drenagem, usualmente assumem que o dreno tubular é completamente permeãvel e não oferece resistência à en trada da água. Isso na prática se consegue envolvendo o tubo por um material poroso (envelope) mais permeāvel que o solo e que aumenta o seu raio de ação. Por outro lado, o efeito contrário, de redução do fluxo de entrada causado pelos orifícios ou perfurações do dreno é bem reconhecido por vārios autores, em função da disposição e tamanho dessas perfurações.

Outro efeito benéfico do envelope ao redor do dreno que tem sido observado por vários autores é a possibi: lidade de aumentar o espaçamento em relação aos drenos sem envelope e em condições de fluxo permanente ou steady-state, como mostram DENNIS e TRAFFORD (1975)。

Entretanto convém lembrar que em nossas condi-.. cões de campo o fluxo em direção aos drenos é essencialmente e quase exclusivamente do tipo não permanente sujeito a recargas que dificilmente são igualados ao mesmo tempo pela descarga dos drenos o que inviabiliza o aumento do espaçamen to apesar do envelope segundo CRUCIANI e BOTREL (1986) . 


\section{MATERIAIS E MÉTODOS}

\subsection{Materiais}

o experimento foi montado em Campo Grande, em lugar ao abrigo da influência de fatores adversos externos, 'utilizando os seguintes materiais:

\section{Caixas (recipientes)}

Foram utilizadas caixas construidas em alvenaria com dimensões de $1,0 \mathrm{~m}$ de altura por $0,7 \mathrm{~m}$ de largura e $0,7 \mathrm{~m}$ de profundidade. Na parede frontal através de uma abertura foi instalado o dreno tubular cuja base estava a 0,2 m do fundo da caixa e, em seguida todas as aberturas foram devidamente fechadas conforme mostram as Figuras 4 e 5 . 
SKAGGS e TANG (1979), aplicaram soluçōes numéricas da equação de RICHARDS que é a equação fundamental para o fluxo de água tridimensional em solo saturado para determinar os efeitos do diāmetro de drenos tubulares, a abertura e envelope no rebaixamento do nível freático em condições de fluxo saturado e não saturado em direção aos drenos.

Concluiram, os citados autores, que o envelope permite um aumento do espaçamento dos drenos sem reduzir a taxa de rebaixamento do nível freático. Entretanto, esse aumento permissível é bastante pequeno. O rebaixamento na parte central entre dois drenos mostrou-se relativamente insensível a mudança de diâmetro dos tubos. Finalmente verificaram que o efeito do diâmetro na descarga depende do espaçamento, da geometria do perfil e das propriedades hidráulicas do solo. Nesse trabalho foram usados drenos convencionais com número finito de perfurações nas paredes e assumidos como tubos completamente abertos, de raio efetivo $r_{e^{\prime}}$ de mane ra semelhante ao trabalho realizado por BRAVO e SCHWAB (1975). Como noutros, nesse trabalho, não houve variação de número de perfurações entre os tubos. 


\section{Drenos}

Cada dreno era constituido de um tubo de PVC de $1,0 \mathrm{~m}$ de comprimento e $100 \mathrm{~mm}$ (4") de diâmetro, parede lisa e de $2,5 \mathrm{~mm}$ de espessura contendo de 36 a 72 orifícios (furos) de $1 / 2$ polegada de diāmetro equidistantes de $3,1 \mathrm{~cm}$. A disposição dos orifícios está indicada na figura 1.

Seçāo Transversal

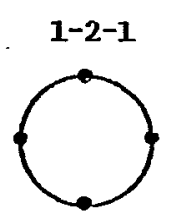

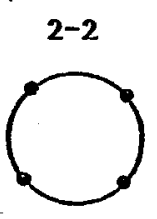

(a)
Seçāo Longitudinal

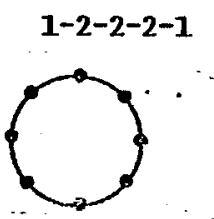

I-II -III -IV -V-VI-VIFVIIIIIX

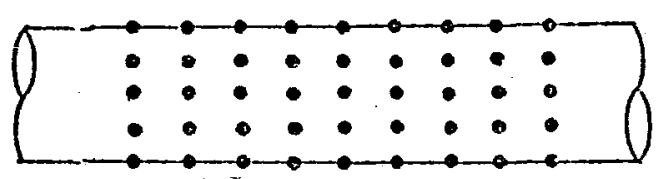

(b)

Figura 1 - (a) Disposição dos orifícios em cada secção tran versal do areno (colunas).

(b) Disposição dos orifícios ao longo da secção longitudinal do dreno, em nove seções transversais ou colunas (I a IX), oito filas, tota lizando 72 orifícios ou furos.

Segundo a Figura acima, cada secção transversal ou coluna continha 8 orifícios que podiam ser abertos em posições diferentes. Assim foram analisadas as posições (12-1) e (2-2) para quatro furos e as posições (1-2-2-2-1) para oito furos.

Cada orificio podia ser fechado ou aberto com a remoção de uma rolha de borracha, pela parte interna do 
tubo, de maneira a obter uma geometria desejável de 1 a 36 ou 72 furos, segundo as curvas transversais de furos utiliza das.

\section{Solo}

Foram utilizados um solo Latossolo vermelho amarelo (LVm) cujas propriedades físicas estão na Tabela 1 e um solo arenoso cuja granulometria se encontra na Tabela 2 .

Tabela 1 - Propriedades físicas e hídricas do solo Latossolo Vermelho Amarelo (LVm) (média de 3 amostras).

\begin{tabular}{ll}
\hline Volume da amostra & $=68,7 \mathrm{~cm}^{3}$ \\
\hline q em volume & \\
esat & $=54,7 \%$ \\
e $_{\text {cc }}$ & $=40,0 \%$ \\
$\alpha$ & $=14,7 \%$ \\
$\gamma_{s}$ & $=1,108 / \mathrm{cm}^{3}$ \\
\hline
\end{tabular}


Tabela 2 - Análise granulométrico do solo arenoso

\section{Areia}

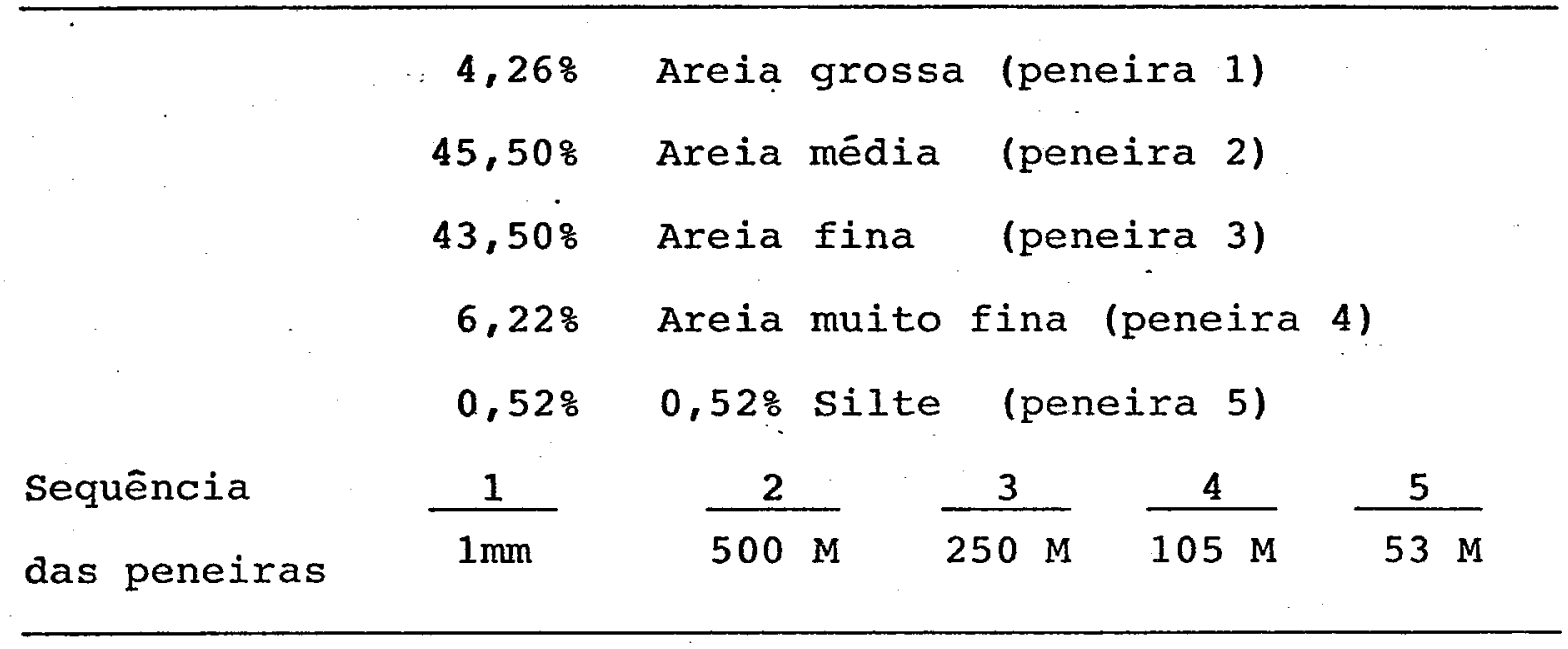

Envelope

Era constituido de uma manta de fibra de poliéster fabricada pela Rhodia do Brasil, denominada de manta Bidin, de código op-30, ou seja de densidade $300 \mathrm{gr}$, por metro quadrado e com aproximadamente $3 \mathrm{~mm}$ de espessura.

\section{Material de Medição}

Cronômetro com precisão de centésimo de segundo

Proveta de $100 \mathrm{ml}$

Erlenmeyer de $400 \mathrm{ml}$

Recipientes de 5 lts para coletas maiores

Balança com precisão de miligramas. 


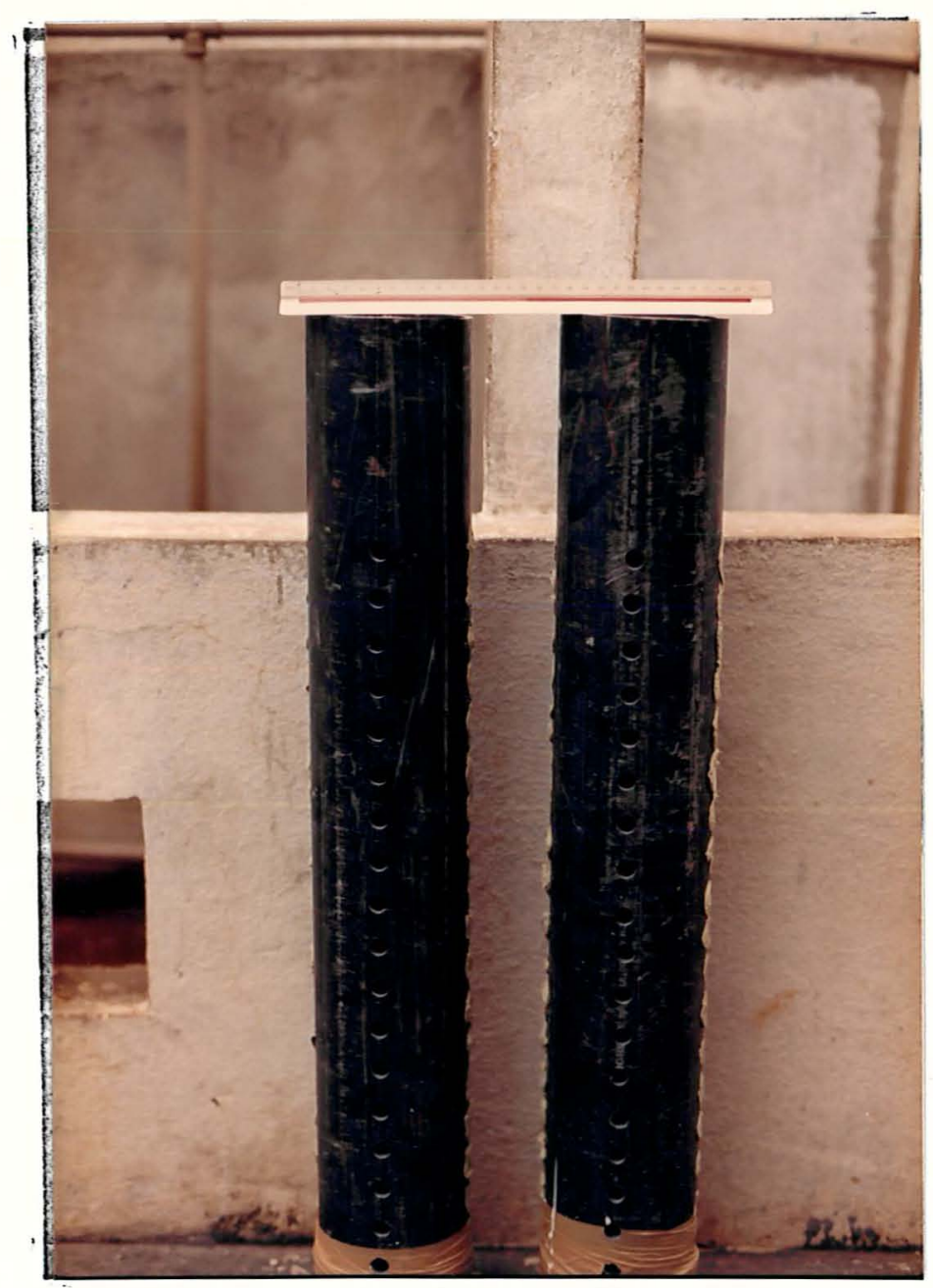

Figura 2 - Os tubos com as linhas de perfurações 
.26 .

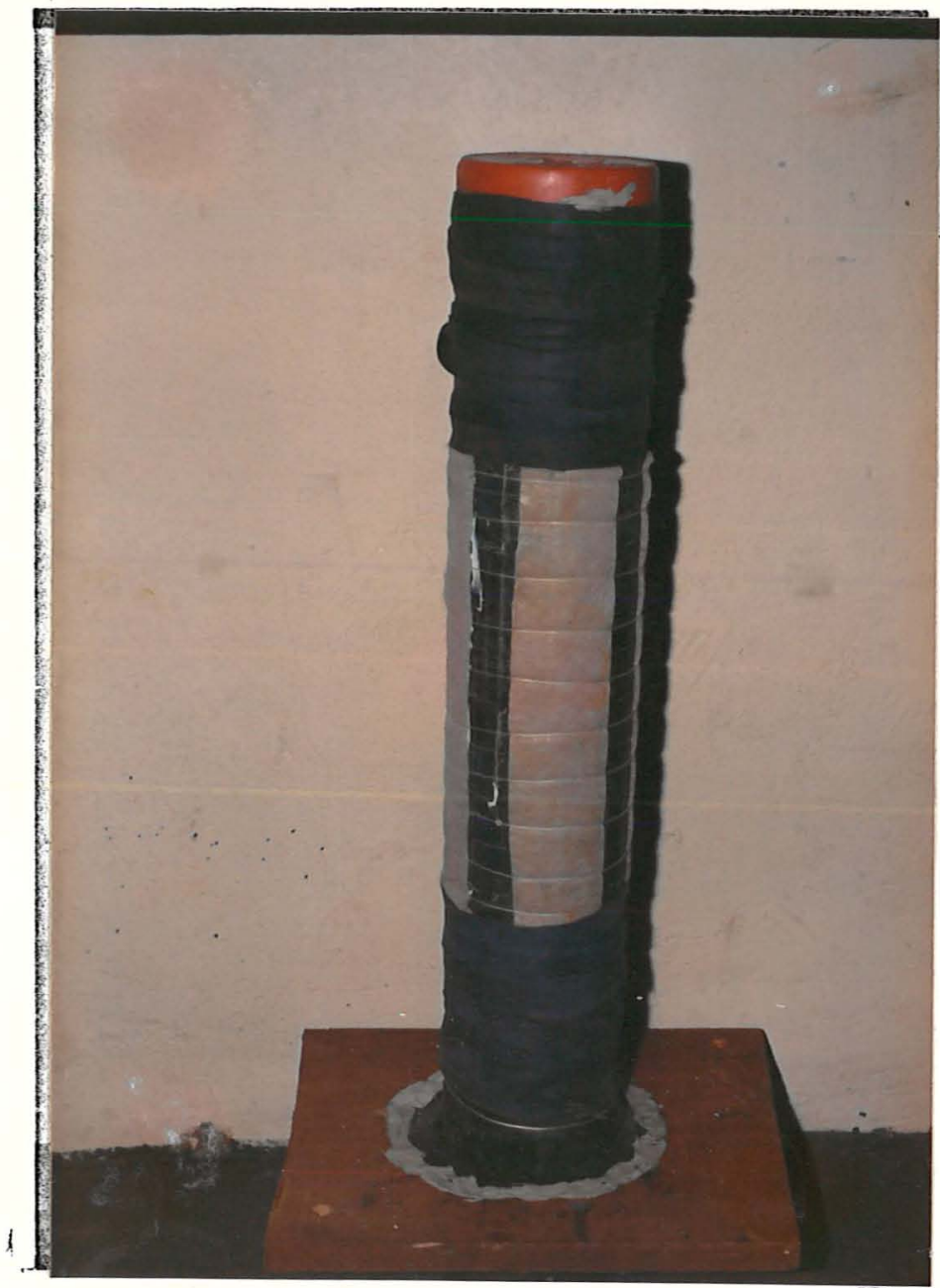

Figura 3 - Tubo perfurado recoberto com manta de Bidim 


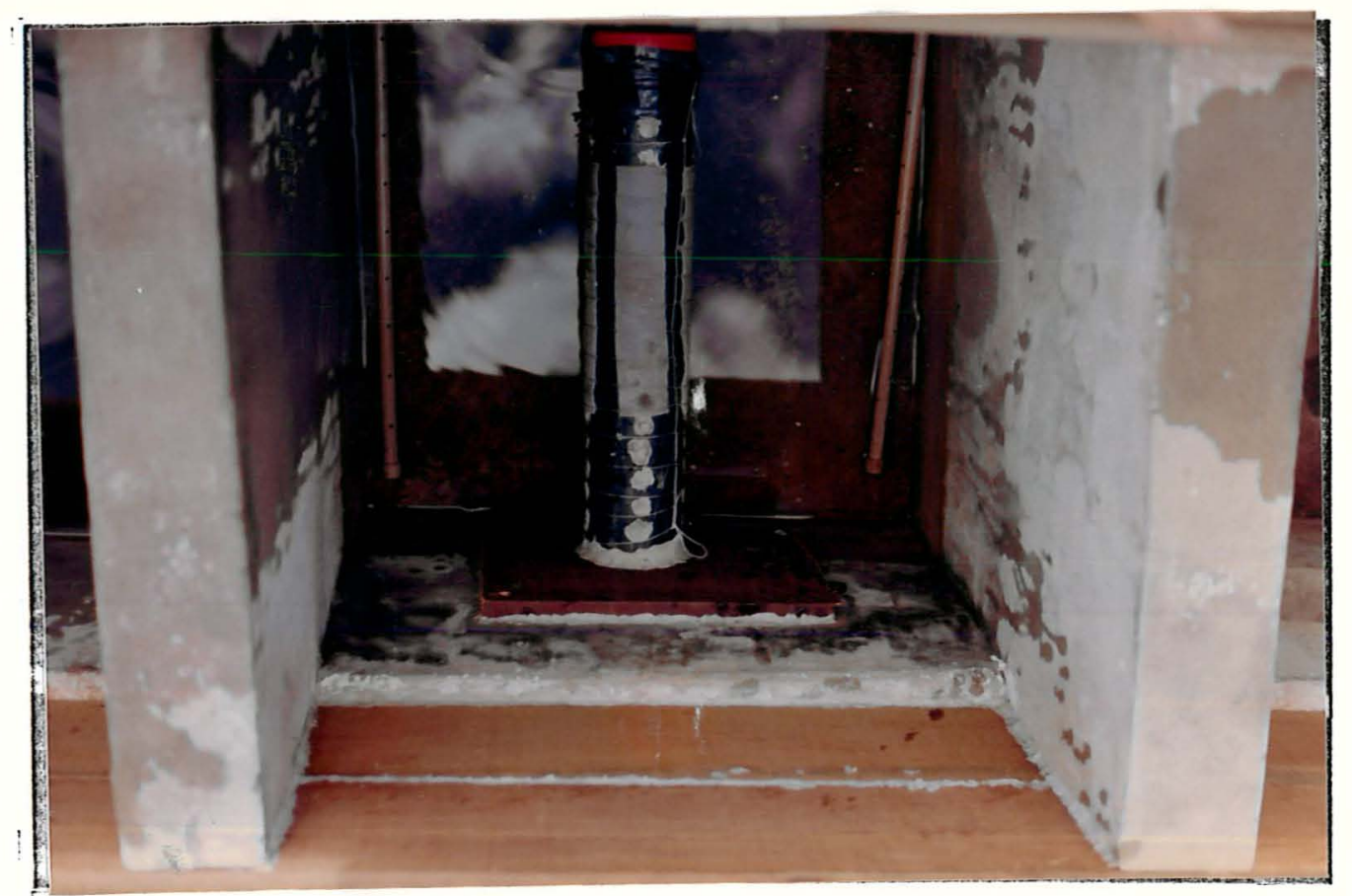

Figura 4 - o tubo instalado na caixa dos experimentos

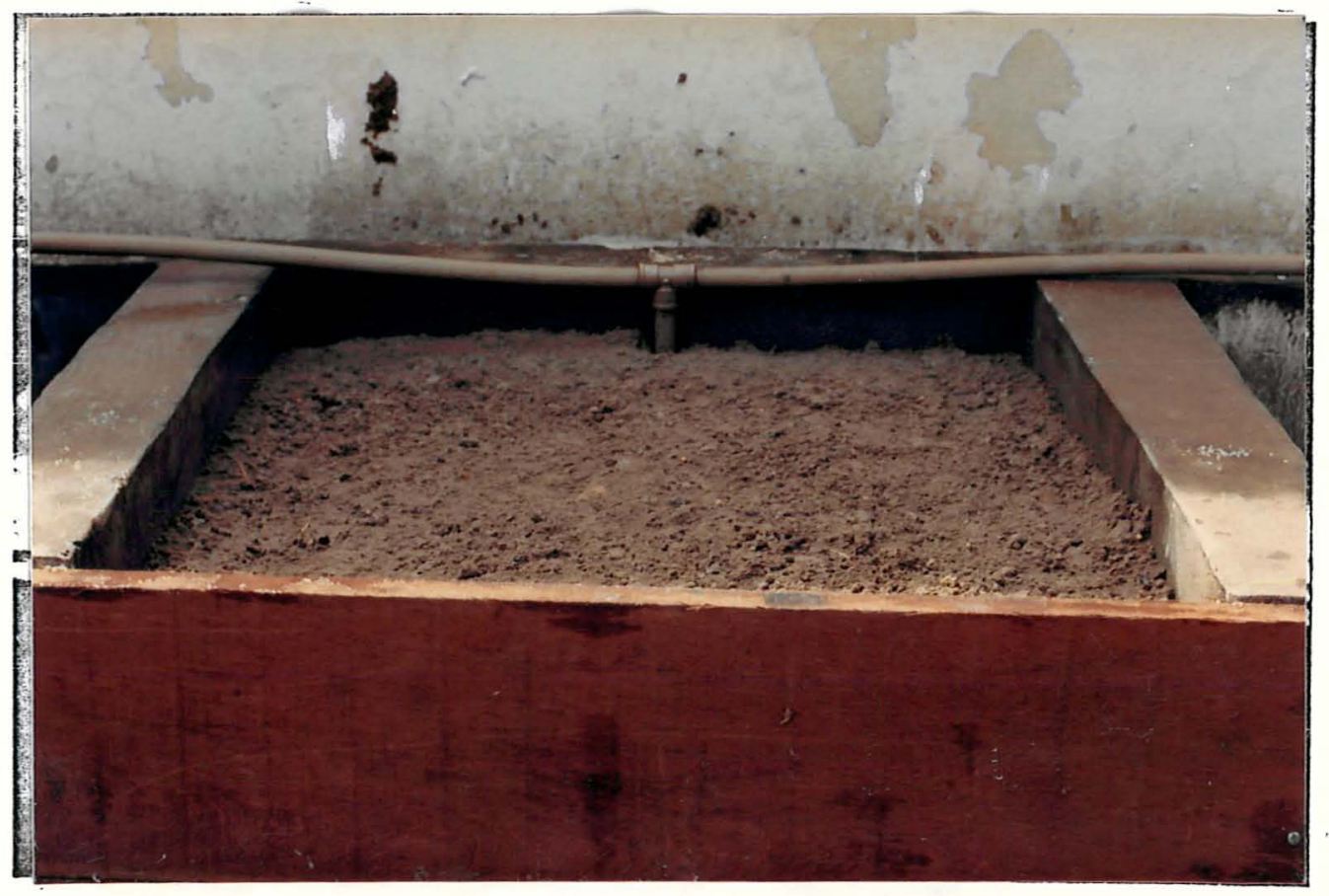

Figura 5 - A caixa de experimento com solo 


\subsection{Métodos}

\section{Colocação do Envelope}

A manta foi fixada em faixas de $5 \mathrm{~cm}$ de largura aproximadamente e de comprimento suficiente para recobrir as filas longitudinais dos furos, sendo colocada com auxilio de cola adesiva em torno do diâmetro externo do furo para evitar o deslocamento de água entre a manta do bidim e a pa rede do tubo. Após colocar todas as faixas do bidim, o mesmo foii amarrado com uma corda de nylon, mas tendo o cuidado de passar a mesma no vão que separa os furos conforme mostram as Figuras 3 e 4.

\section{Instalação dos Drenos}

Os drenos foram instalados conforme mostra a Figura 4, na horizontal e guardando equidistância das paredes laterais com os furos dispostos conforme o teste: a ser realizado. Também se manteve a equidistância na coluna do primeiro e último furo em relação às paredes anteriores e pos teriores da caixa.

\section{Preparo das Caixas}

Para preencher duas caixas com solo LVm, em virtude de o mesmo não ter sido destorroado, a cada camada 
de $20 \mathrm{~cm}$ adicionava-se água em excesso de maneira a construir um perfil de solo uniforme dentro da caixa. Usou-se o mesmo processo para as outras duas caixas com solo arenoso. Logo após assentar o material, por 48 horas procedia-se à sua dre nagem através do tubo até o mesmo não apresentar descarga al guma. Considerando o perfil do solo estar uniforme, se fecha va o tubo de descarga e procedía-se à sua saturação no sentí do de baixo para cima através de dois tubos perfurados colocados na base da caixa conectados a uma mangueira de água pa ra sua alimentação. Quando o nível de água chegava acima da superficie do solo e atingia uma carga desejada conforme o programa do teste a ser medido, cortava-se a entrada da água pela parte inferior da caixa, colocava-se uma entrada de água pela parte superior da caixa no mmomento dos testes de forma a manter uma carga hiâráulica constante..

\section{Proceđimentos das Leituras}

Para manter a simetria que envolve a geometria de perfurações no areno se procedia a abertura dos furos da seguinte maneira: a) quando se tratava da abertura de uma fi la, por exemplo, superior, inferior ou lateral a primeira medida era feita abrindo-se os furos $I$ e IX: Logo a seguir o furo intermediário entre os mesmo; o furo V. Seguia-se a sequência abrindo os pontos intermediärios entre os mesmos furos III e VII. Por fim a totalidade dos furos dessa linha. 
b) quando se procedia a abertura duas, três ou todas as 1inhas procedia-se na mesma sequência de abertura; primeiro os furos I e IX em todas às colunas ou seç̧ões; logo a seguir os furos nas linhas $V$, depois III e VII e por último todos das linhas que estavam sendo testadas.

Testes Preliminares

Para verificar se a manta de bidim limitaria a condutividade hidráulica dos solos, foram feitos ensaios de vazão dos furos com a manta de bidim em água pura e foi verí ficada ainda a validade da fórmula da vazão em orifícios para determinar a vazão dos furos: rar a vaz

$$
Q=C d \cdot A \cdot \sqrt{2 g h}
$$

Para conferir as medidas encontradas com os re sultados teóricos de hidráulica se procedeu à leitura por fú ros abertos sem a presença do envelope de bidim.

Sendo: $Q=$ vazão $\mathrm{em} \mathrm{m}^{3} / \mathrm{seg}$.

$$
\begin{aligned}
& \mathrm{A}=\text { área em } \mathrm{m}^{2} \cdot \mathrm{Cd}=\text { coeficiente de descarga } \\
& \mathrm{g}=\text { gravidade } \\
& \mathrm{h}=\text { altura em metros (carga- hidráulica) }
\end{aligned}
$$

Exemplo: diâmetro do furo $=1 / 2 "=1,-27 \mathrm{~cm}$,

$$
\text { altura }(\mathrm{h}) \quad=0,50 \mathrm{~m}
$$




$$
\begin{aligned}
A & =\frac{D^{2} \pi}{4}=0,000127 \mathrm{~m}^{2} \\
Q & =0,000127 \times 0,61 \times 9,80 \times 0,50= \\
& =0,000242 \mathrm{~m}^{3} / \mathrm{seg} \\
Q & =242 \mathrm{ml} / \mathrm{seg}
\end{aligned}
$$


4. RESULTADOS E DISCUSSÃO

\subsection{Resultados dos testes preliminares sem Bidim}

De acordo com a posição dos orifícios numa seç ção transversal do tubo:

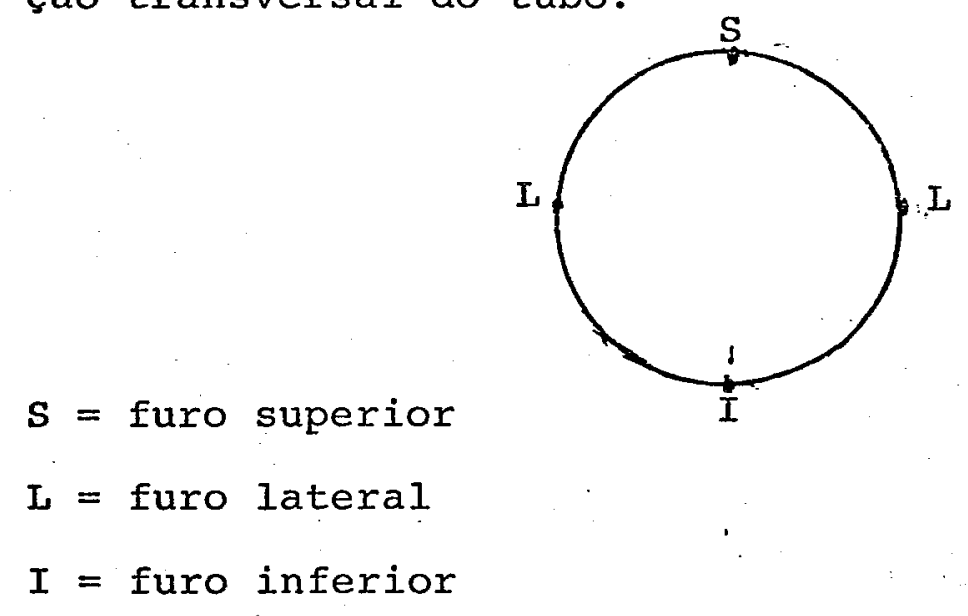

Resultou: 
Tabela 3 - Vazão por furo sem cobertura de bidim

\begin{tabular}{cccc}
\hline Furo & $Q^{*}$ medida & $Q^{*}$ calculada & Diferença (\%) \\
\hline S & 237 & 242 & 2,1 \\
L & 248 & 254 & 2,4 \\
I & 260 & 266 & 2,3 \\
\hline
\end{tabular}

$Q^{*}=$ vazão em $\mathrm{ml} / \mathrm{seg}$

- Portanto, o valor do coeficiente "C" $(=0,61)$ encontrado neste caso foi de $0,596=0,60$ para que a vazão encontrada e a calculada, no teste, sejam equivalentes.

Somando os furos abertos ${ }^{S}$ individualmente e realizados em conjunto nos deu o seguinte:

Tabela 4 - Vazão por furos abertos simultaneamente sem cober tura de bidim.

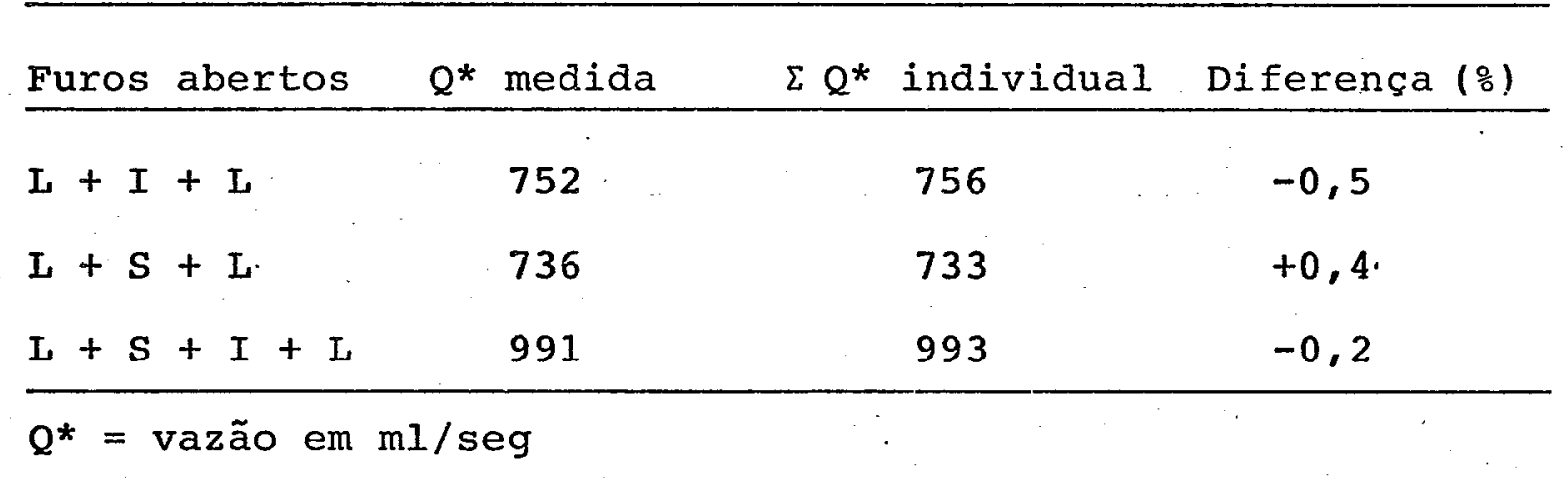


Tabela 5 - Vazão por furo individual e coletivo com cobertura de bidim.

\begin{tabular}{cccc}
\hline $\begin{array}{c}\text { Furos } \\
\text { abertos }\end{array}$ & $\begin{array}{c}\mathrm{Q}^{*} \text { medida } \\
\text { (com bidim) }\end{array}$ & $\begin{array}{c}\mathrm{Q}^{*} \text { medida } \\
\text { (sem bidim) }\end{array}$ & $\begin{array}{c}\text { Percentagem } \\
(\%)\end{array}$ \\
\hline $\mathrm{S}$ & $71 \mathrm{ml} / \mathrm{seg}$ & $237 \mathrm{ml} / \mathrm{seg}$ & 29,96 \\
$\mathrm{~L}$ & $70 \mathrm{ml} / \mathrm{seg}$ & $248 \mathrm{ml} / \mathrm{seg}$ & 28,23 \\
$\mathrm{I}$ & $83 \mathrm{ml} / \mathrm{seg}$ & $260 \mathrm{ml} / \mathrm{seg}$ & 31,92 \\
$\mathrm{~L}+\mathrm{I}+\mathrm{L}$ & $192 \mathrm{ml} / \mathrm{seg}$ & $752 \mathrm{ml} / \mathrm{seg}$ & 25,53 \\
$\mathrm{~L}+\mathrm{S}+\mathrm{I}$ & $192 \mathrm{ml} / \mathrm{seg}$ & $736 \mathrm{ml} / \mathrm{seg}$ & 26,09 \\
$\mathrm{~L}+\mathrm{S}+\mathrm{I}+\mathrm{L}$ & $228 \mathrm{ml} / \mathrm{seg}$ & $991 \mathrm{ml} / \mathrm{seg}$ & 23,01 \\
\hline $\mathrm{Q}=\mathrm{vazão} \mathrm{em} \mathrm{ml/seg}$ & &
\end{tabular}

Calculando a média aritmética ponderada das percentagens da diferença entre a vazão encontrada com e sem bidim temos o valor de $25,92 \%$.

Essa percentagem $(25,92 \%)$ é a quantidade de água que passa pelo furo coberto com bidim em relação a sem a cobertura do bidim.

Com a vazão $Q=$ área (em metros quadrados) $\mathrm{V}=$ velocidade (em metros por segundo) teremos:

$$
\begin{aligned}
& Q=A \times V \\
& V=Q / A=0,000237 / 0,000127=V=1,87 \mathrm{~m} / \mathrm{seg} .
\end{aligned}
$$

seguindo sempre com valores do teste.

Como o valor da permeabilidade é de $25,92 \%$ des se valor teremos que: 
- A diferença entre a somatória das laterais e a inferior abertos em relação a somatória das laterais e a superior também abertos foi de 0,9\%. E devido a que quando abertos os furos das laterais em conbinação com 0 furo inferior o jato de água provocado pelos furos laterais, com essa carga hidrâulica, incide diretamente sobre o furo inferior reduzindo a vazão do furo inferior (logicamente que os furos estão na mesma fila da seçãa do tubo).

Pelo exposto anteriormente pode-se deduzir que os cálculos téoricos se confirmam com os resultados encontra dos nos testes com água e sem bidim.

4.2. Medidas de descarga do dreno com envelope de bidim e carga hidráulica constante

Da mesma forma que foi realizado o teste anterior é feito agora mas com a cobertura do envelope de bidim para encontrar a velocidade de permeabilidade deste elemento que envolve o dreno. A seguir temos a vazão medida com envelope de bidim em comparação com o teste anterior sem envelope. 


$$
\mathrm{v}=0,4847 \mathrm{~m} / \mathrm{s}
$$

- que podemos ver pelos testes que seguem com diversos materiais que todos eles tem velocidade de permeabilidade muito menores.

Pelos resultados encontrados pode-se deduzir que o recobrimento dos drenos com bidim não reduz a permeabi lidade do solo, mesmo que este seja de areia pura e que possua uma permeabilidade acentuada.

4.3. As medições do dreno com envelope de bidim no solo Arenoso e solo Latossolo vermelho amarelo

As medições de descarga, conforme se vē nos re sultados dos testes descritos nos Quadros I e II, sempre guardaram uma ordem de sequência de abertura dos orificios de forma a manter a simetria entre orificios, sejam abertos ao longo de uma fila ou de várias filas ao mesmo tempo.

\section{Seja por exemplo, no Quadro I:}

camada do solo saturado $67 \mathrm{~cm}$ com uma lâmina de água de $1 \mathrm{~cm}$ acima do nỉvel do mesmo, perfazendo $68 \mathrm{~cm}$ de cargas hidráulica para a posição dos furos 1-2-1. As filas abertas podiam ser na posição (S) superior, (I) inferior ou (S+I) superior mais inferior juntás, etc. Dessa forma temos a primeira abe $\underline{\underline{r}}$ tura dos furos na fila indicada (S) com as secções verticais extremas I e IX conforme mostra a Figura 1 (b). Teremos, então a vazão em $\mathrm{ml} / \mathrm{min}$ dos furos abertos ( $\mathrm{I}$ e IX superiores), 
enfim a média por furo. Continuando calculou-se a permeabilí dade do furo em metros por dia e o que seria a vazão para 100 metros de tubulação em metros cúbicos por dia.

Ainda seguindo o mesmo exemplo, no passo seguinte o número de orifícios abertos aumentou para três, na mesma fila de posição $S$ pois foi incluida a secção transversal situada na coluna $\mathrm{V}$ ou $(I-V-I X)$, repetindo os cálculos como anteriormente. A seguir foram abertos os orificios (S) situados nas seç̧ões transversais ou colunas III e VII e finalmente todos os situados na mesma fila.

Todas as leituras foram feitas com diversas ca madas dos dois tipos de solos respectivamente mencionados, va riando a lâmina de água acima do nível do solo e obtendo car gas hidráulicas variadas, além da variação da posição e do número de orifícios abertos.

Os resultados obtidos durante a realização do presente estudo estão reunidos nos Quadros I e II, sendo res pectivamente, com uso do solo arenoso, e com Latossolo Vermelho Amarelo. 
Quadro I - sintese dos testes realizados com areia e envelope de bidim.

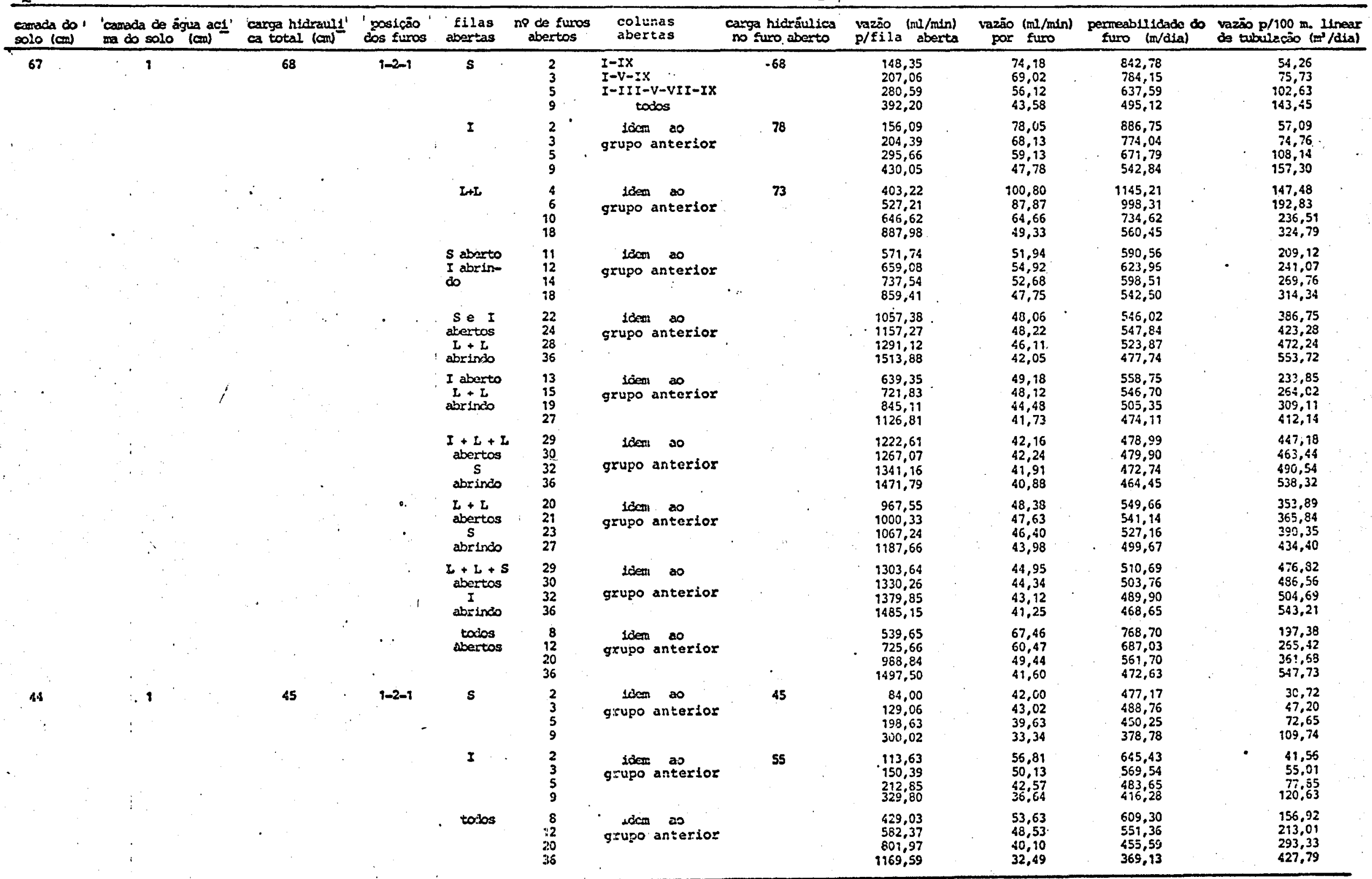


continuação do Quadro I

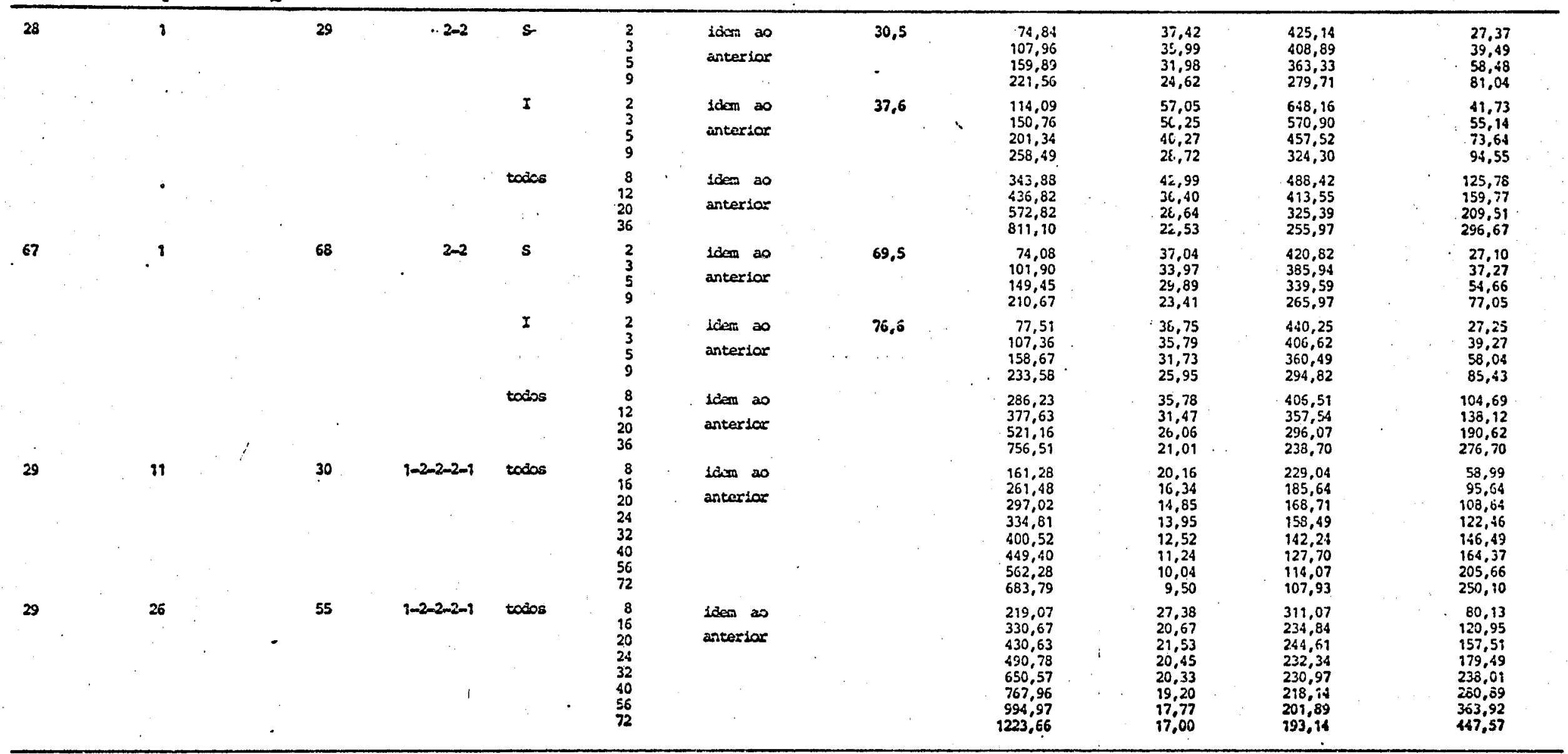


Quadro II - Sintese dos testes realizados com Latossol e envelope de Bidim.

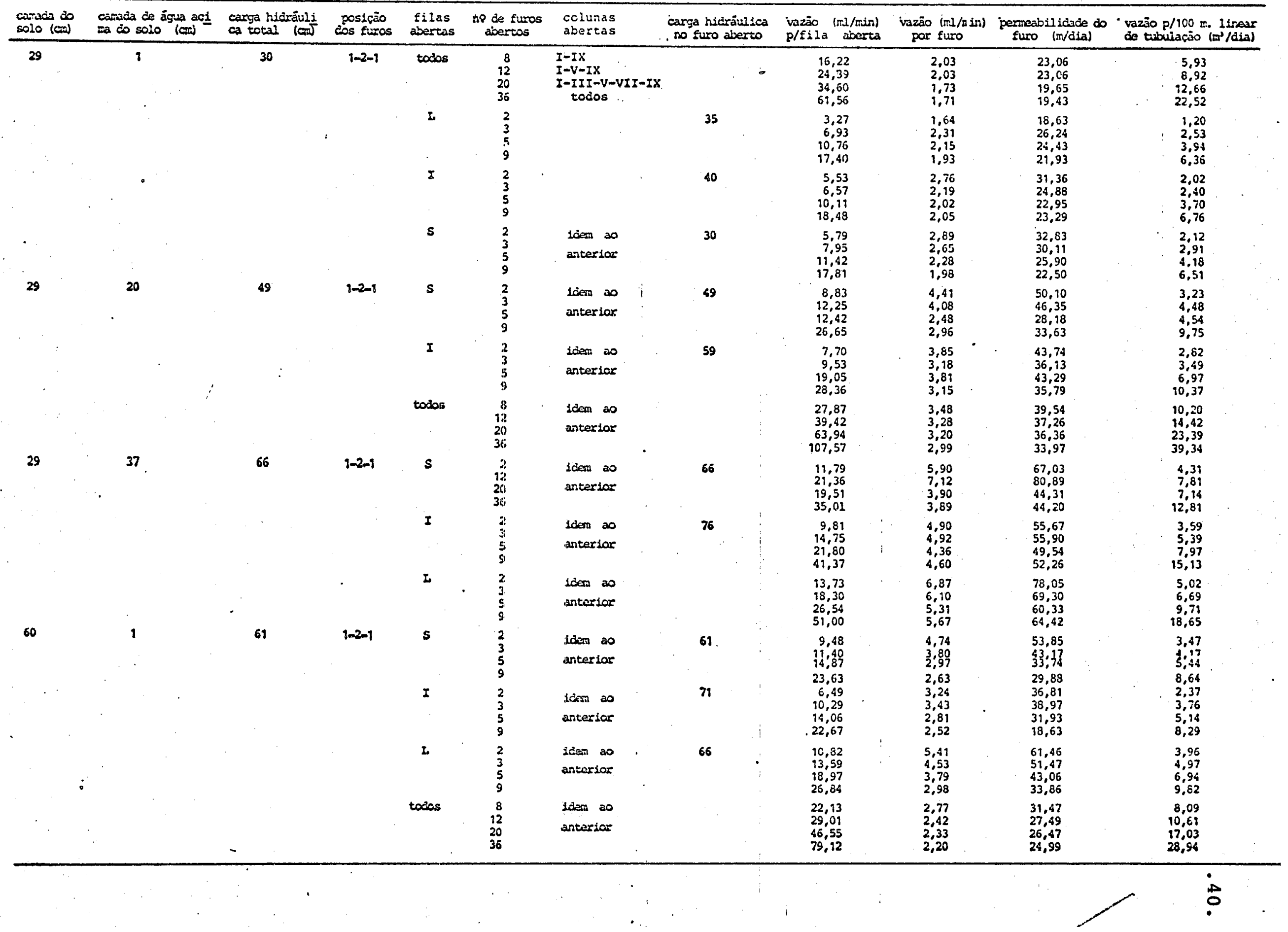




\begin{tabular}{|c|c|}
\hline \multirow[t]{2}{*}{$12-9$} & $s$ \\
\hline & I \\
\hline & L \\
\hline . & todos \\
\hline & \\
\hline $1-2-8$ & $s$ \\
\hline & $I$ \\
\hline
\end{tabular}

2

1

50

17

66

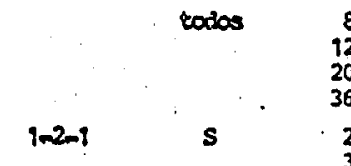

49

20

$49 \quad 1-2-2-2-1$ todos

29

66 i-2-2-2-1 todos

37

29 anterio:

idem ao

anterior

10 en $\infty$

antertor

idem as

anteriar

sodern no

anteriar

idem as

anteriar

$10 \mathrm{am} \infty$

anterior

Idem ao

anteriox

icem 20

anterior

Licer as

anteriar

iden as

anteriar

idem as

anterior
66

66

5,8
7,60

7,60
12,00
22,96

76

71

5,39
7,17

9,43
98,87

5,32
7,94
12,74

12,74
19,33

18,10

29,21

47,89
84,02

50

3,45

3,35
8,78
8,78

8,78
16,47

60

5,49

5,07
9,78
15,79
16,94

16.94

16,94
23,53
36,52

4,29
7,75
71,72

66

11,72
22,80

76

5,21
8,12

8,12
10,78
20,55

11,52

33,94
53,44

$\therefore \quad 2,48$

$1,29 \quad 0,16$

$\begin{aligned} & 2,80 \\ & 3,20\end{aligned} \quad 0,17$

3,20
3,70

5,08
6,40

8,65
10,78

1,27
2,49
3,05

3,05
4,11
5,86

7.49
10,84

10,84
13,95

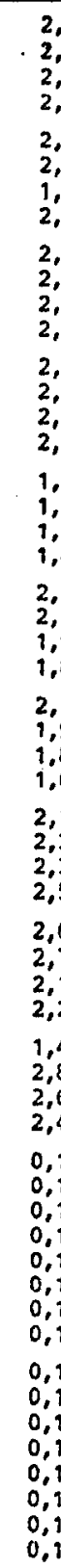

32,95
28,74

27,74
28,97

30,56
27,15
21,47

23,86

30,22
30,45

30,45
28,97

24,43

25,68

27,61

27,15
26,47

19,54

20,34 20,00
20,79

31,24

22,95

21,25

24,09

22,27

20,79
19,09

24,31

27,04

26,59

28,74

30,79

24,54

25,90

76,34

32,15

30,33
28,18

1,82
1,93
1,82

1,82

1,70
1,82
1,82

1,70

1,70

1,82
1,82

1,70
1,93
2,05

2,05
2,16

2,16
2,16
2,13

4,39

1,97

1,26
1,97

1,97
3,21
6,02

2,09

2,22
3,58
6,14

6,14

6,20

8,61
13,36

22,15

1.57

2,62
4,29

8,34

1,91
2,97

3.94

7,52

4,21

$\$ 9,55$

32.71

0.47

1,17

1,35
1,86

2,34

3,94

0,46
0,91

1,12 


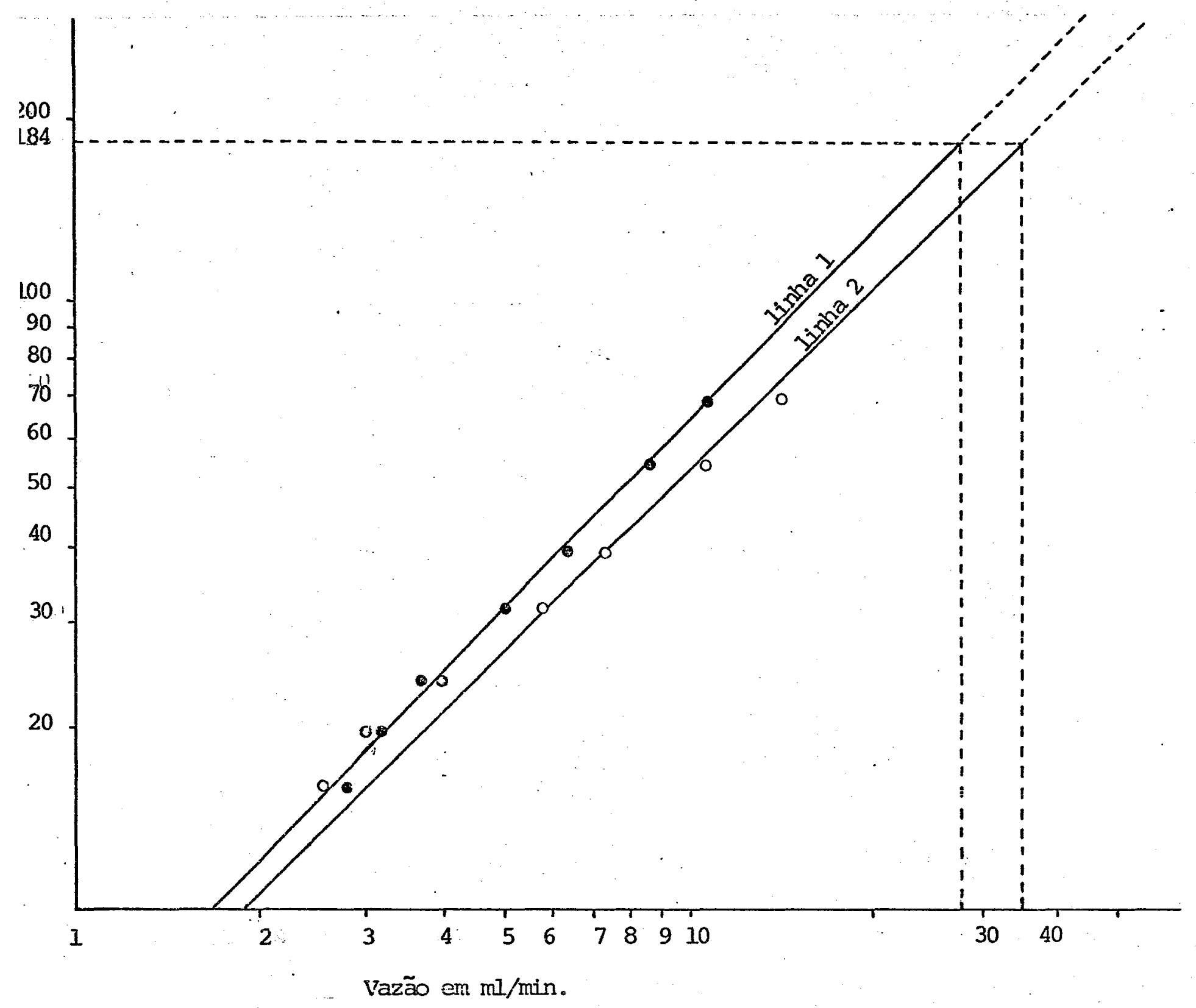

Figura 6 - Gráfico da relação com o no de orifícios para: Linha 1 - camada do solo acima do dreno $(29 \mathrm{~cm})$; nível de água acima da superfície do solo $(20 \mathrm{~cm})$.

Linha 2 - camada do solo acima do dreno $(29 \mathrm{~cm})$; nível de água acima da superfície do solo $(37 \mathrm{~cm})$. 
Análise Estatistica dos Resultados, em Blocos Casualizados

Material: Areia

Camada do solo: $67 \mathrm{~cm}$ sobre a parede superior do dreno

Carga de água: $1 \mathrm{~cm}$

Posição dos furos: 1-2-1

As conđições de abertura dos orifícios nos dre nos seguem a ordem representado pelas letras $\mathrm{M}-\mathrm{N}-\mathrm{Z}-\mathrm{K}$ cujo significado, de acordo com a Figura 1, é:

M - secções Transversais I - IX

N - secções Transversais I - V - IX

z - secções Transversais I - III - V - VII - IX

K - todos os orifícios abertos na linha

Temos ainda que:

S - parte superior do tubo

- I - parte inferior do tubo

L - parte lateral do tubo 
Tabela 6 - Demonstrativo de vazões (ml/min)

\begin{tabular}{cccccc}
\hline & $\mathrm{M}$ & $\mathrm{N}$ & $\mathrm{Z}$ & $\mathrm{K}$ & Totais \\
\hline $\mathrm{S}$ & 74,18 & 69,02 & 56,12 & 43,58 & 242,90 \\
$\mathrm{I}$ & 78,05 & 68,13 & 59,13 & 47,78 & 253,09 \\
$\mathrm{~L}$ & 100,80 & 87,87 & 64,66 & 49,33 & 302,66 \\
\hline TOTAIS & 253,03 & 225,02 & 179,91 & 140,69 & 798,65 \\
MEDIAS & 84,34 & 75,00 & 59,97 & 46,89 & \\
\hline
\end{tabular}

- As parcelas representam a vazão média por furo (ml/min).

Da Tabela 6 resulta:

Tabela 7 - Análise de variância.

\begin{tabular}{|c|c|c|c|c|}
\hline & GI & $\mathrm{SQ}$ & $Q M$ & $\mathbf{F}$ \\
\hline Blocos & 03 & 2453,00 & 817,67 & $23,76 \$ \$$ \\
\hline Tratamentos & 02 & 511,03 & 255,52 & $7,42 \$$ \\
\hline Residuo & 06 & 206,52 & 34,42 & \\
\hline TOTAL & 11 & 3170,55 & & \\
\hline$C=53.153,48$ & & & & \\
\hline $\begin{array}{l}\text { SQ total }=\Sigma \\
\text { SQ blocos }=2\end{array}$ & $2-$ & $=3.170$ & .. & \\
\hline SQ tratam.= & 1,0 & & & \\
\hline
\end{tabular}




$$
\begin{aligned}
& \mathrm{f}_{3 ; 6 ; 0,05}=4,76 \\
& \mathrm{f}_{3 ; 6 ; 0,01}=9,78 \\
& \mathrm{f}_{2 ; 6 ; 0,05}=5,14 \\
& \mathrm{f}_{2 ; 6 ; 0,01}=10,92
\end{aligned}
$$

Desdobramento do número de grau de liberdade de tratamento.

$$
S \times I \quad \text { e. } \quad(S+I)+I
$$

a. $S \times I$

tratamento $\mathrm{S}=242,90$

$S Q(S \times I)=1 / 4\left[(242,90)^{2}+(253,09)^{2}\right]-1 / 8(495,99)^{2}$

tratamento $I=253,09$

SQ $(S x I)=30.763,73-30.750,76=12,97$

b. $(S+I) \times I$

$S+I=495,99$

$$
L=302,66
$$

$S Q[(S+I) \times L]=1 / 8(495,99)^{2}+1 / 4(302,66)^{2}-C=49.8,04 / 3$ 
Tabela 8 - Análise da variância

\begin{tabular}{lccrc}
\hline CV & GL & SQ & QM & \multicolumn{1}{c}{ F } \\
\hline S X I & 01 & 12,97 & 12,97 & 0,38 \\
$(\mathrm{~S}+\mathrm{I}) \times \mathrm{L}$ & 01 & 498,06 & 498,06 & $14,47 \mathrm{~s}$ \\
(tratamento) & $(02)$ & 511,03 & & \\
blocos & 03 & 2453,00 & & \\
residuo & 06 & 206,52 & 34,42 & \\
\hline TOTAL & 11 & & & \\
\hline
\end{tabular}

Notamos que os tramentos S e I apresentaram juntos uma maior vazão por furo do que o L.

Os tratamentos S e I não diferem estatisticamente.

Considerando as médias $\bar{M}_{;}, \bar{N}_{;}, \bar{Z}_{;}, \overline{\mathrm{K}}$ onde existe uma diferença altamente significativa entre as mesmas.

$$
\begin{aligned}
& \overline{\mathrm{M}}=84,34 \\
& \overline{\mathrm{N}}=75,00 \\
& \overline{\mathrm{Z}}=59,97 \\
& \overline{\mathrm{K}}=46,89
\end{aligned}
$$


Apliquemos o método de TUKEY a $5 \%$.

$$
\begin{array}{ll}
\Delta=\mathrm{q} / \mathrm{s} \quad \text { onde } & \mathrm{s}=\sqrt{34,42}=5,87 \\
\Delta=4,90 \frac{5,87}{\sqrt{3}} & \mathrm{q}=4,90 \mathrm{r}=3 \\
\Delta=16,60 \text { (d.m.s.) } &
\end{array}
$$

Tabela 9 - Comapração entre às médias

\begin{tabular}{ccccc}
\hline & $\overline{\mathrm{M}}$ & $\overline{\mathrm{N}}$ & $\overline{\mathrm{Z}}$ & $\overline{\mathrm{K}}$ \\
\hline$\overline{\mathrm{M}}$ & - & 9,34 & 24,37 & 37,45 \\
$\overline{\mathrm{N}}$ & - & - & 15,03 & 28,11 \\
$\overline{\mathrm{Z}}$ & - & - & - & 13,08 \\
$\overline{\mathrm{K}}$ & - & - & - & - \\
\hline
\end{tabular}

- Observamos que a média $\bar{M}$ difere significativamente das médias $\overline{\mathrm{Z}}$ e $\overline{\mathrm{K}}$ e a média $\overline{\mathrm{N}}$ difere somente da média $\overline{\mathrm{K}}_{\boldsymbol{i}}$ isto é, os tubos nas condições $\bar{M}$ apresentam uma maior vazão por fuㅡ ro do que os mesmos nas condições $z$ e $K$.

Notamos que a medida que se aumenta $\circ$ número de furos por tubo, diminui-se a vazão por furo individual.

Consideramos a Tabela 10 onde os tratamentos são os seguintes:
$A$ = Superior aberto - inferiores
$B=$ Superior e inferior abertos - 2 laterais
$\mathrm{C}=$ Inferior aberto -2 laterais 
D = Inferior e 2 laterais abertos - superior

$E=2$ Laterais e superiores abertos - inferiores

$\mathbf{G}=$ Todos abertos

Tabela 10 - Demonstrativo de vazões

\begin{tabular}{cccccc}
\hline & M & N & Z & K & Totais \\
\hline A & 51,98 & 54,92 & 52,68 & 47,75 & 207,33 \\
B & 48,06 & 48,22 & 46,11 & 42,05 & 184,44 \\
C & 49,18 & 48,12 & 44,48 & 41,73 & 183,51 \\
D & 42,16 & 42,24 & 41,98 & 40,98 & 167,26 \\
E & 48,38 & 47,63 & 46,40 & 43,98 & 186,39 \\
F & 44,95 & 44,34 & 43,12 & 41,25 & 173,66 \\
G & 67,46 & 60,47 & 49,44 & 41,60 & 218,97 \\
\hline TOTAL & 352,17 & 345,94 & 324,21 & 299,24 & $1.321,56$ \\
\hline MEDIAS & 50,31 & 49,42 & 46,32 & 42,75 & \\
\hline
\end{tabular}

Resulta então a Tabela seguinte:

Tabela 11 - Análise de variância

\begin{tabular}{lcccc}
\hline CV & GL & SQ & SM & F \\
\hline Blocos & 03 & 246,39 & 82,13 & $5,77 * *$ \\
Tratamentos & 06 & 499,90 & 83,32 & $5,86 * *$ \\
Resíduos & 18 & 256,08 & 14,23 & - \\
\hline TOTAL & 27 & $1.002,37$ & & \\
\hline
\end{tabular}


$C=62.375,74$

SQ Total $=63.378,11-62.375,74=1.002,37$

SQ Blocos =

SQ Trat. $=499,90$

O teste $\mathrm{f}$ a 58 nos dá $\mathrm{F}_{3 ; 18}=3,16$ e $\mathrm{F}_{6,18}=2,66$

a 1q. nos dá $F_{3 ; 18}=5,09$ e $F_{6 ; 18}=4,01$

Observamos que existe uma diferença altamente significativa entre os tratamentos e também entre os blocos. Desdobrando-se o número de graus de liberdade dos tratamentos teremos as interações:

A $X$ Demais

$\mathrm{B} \times \mathrm{C}$

D X E

F X G

$(B+C) \times(D+E)$

$(D+E) \times(F+G)$

$A \times$ Demais $\rightarrow A=207,33$

Demais $=1.114,23$

SQ $(A \times$ Demais $)=1 / 4(207,33)^{2}+1 / 24(1.114,23)^{2}-C=100,1$

$B \times C \rightarrow B=184,44$

$$
C=183,51
$$

$S Q(B \times C)=1 / 4\left[(184,44)^{2}+(183,51)^{2}\right]-1 / 8(367,95)^{2}=0,118$

$D X E \rightarrow D \doteq 167,26$

$E=186,39$

$S Q(D \times E)=1 / 4\left[(167,26)^{2}+(186,39)^{2}\right]-1 / 8(353,65) 2=45,7$ 


$$
\begin{aligned}
& F \times G \rightarrow F=173,66 \\
& S Q=218,97 \\
& B+C \times G)=1 / 4\left[(173,66)^{2}+(218,97)^{2}\right]-1 / 8(392,63)^{2}=256,6 \\
& D+E=353,65 \\
& S Q[(B+C) \times(D+E)]=1 / 8\left[(367,95)^{2}\right]-1 / 16(721,60)^{2}=12,7 \\
& D+E=353,65 \\
& F+G=393,63 \\
& S Q[(D+E) \times(F+G)]+\text { por diferença }=84,7
\end{aligned}
$$

Resulta a Tabela seguinte:

Tabelà 12 - Análise de variância

\begin{tabular}{ccccc}
\hline A & 01 & 100,1 & 100,1 & $7,03(*)$ \\
B X C & 01 & 0,1 & 0,1 & 0,007 \\
D X E & 01 & 45,7 & 45,7 & 3,21 \\
F X G & 01 & 256,6 & 256,6 & $18,03(* *)$ \\
(B+C) X (D+E) & 01 & 12,7 & 12,7 & 0,89 \\
(D+E) X (F+G) & 01 & 84,7 & 84,7 & $5,95(*)$ \\
Tratamento & $(06)$ & 499,90 & 83,32 & - \\
Blocos & 03 & 246,39 & 82,13 & - \\
Residuo & 18 & 256,08 & 14,23 & - \\
\hline
\end{tabular}

TOTAL

$$
F_{1,18 ; 0,05}=4,41 ; \quad F_{1,18 ; 0,01}=8,29
$$


Observa-se que o tratamento A supera os demais, isto é, se os superiores forem abertos e trabalhar-se com os inferiores, mantendo-se os laterais fechados, a vazão será maior.

\section{um resultado altamente significativo é obtido} entre os tratamentos F e G , isto é, há maior vazão com todos os buracos abertos do que somente com os laterais e os superiores abertos.

Aplicando-se TUKEY 5\%, às médias teremos:

$$
\begin{aligned}
& \bar{M}=50,31 \\
& \bar{N}=49,42 \\
& \bar{Z}=46,32 \\
& \bar{K}=42,75
\end{aligned}
$$

$$
\begin{aligned}
& \Delta=q \frac{s}{\sqrt{r}}=4,00 \frac{3,77}{\sqrt{x}}=5,7 \\
& s=\sqrt{14,23}=3,77 \\
& q=4,00 \\
& r=7 \\
& \text { d.m.s. }=5,7
\end{aligned}
$$

Tabela 13 - Comparação de médias

\begin{tabular}{ccccc}
\hline & $\overline{\mathrm{M}}$ & $\overline{\mathrm{N}}$ & $\overline{\mathrm{Z}}$ & $\overline{\mathrm{K}}$ \\
\hline$\overline{\mathrm{M}}$ & - & 0,89 & 3,99 & $7,56(*)$ \\
$\overline{\mathbf{N}}$ & - & - & 3,10 & $6,67(*)$ \\
$\overline{\mathbf{Z}}$ & - & - & - & 3,57 \\
$\overline{\mathrm{K}}$ & - & - & - & - \\
\hline
\end{tabular}


Constatamos que $\bar{M}$ e $\overline{\mathrm{N}}$ diferem significativamen te de $\overline{\mathrm{K}}$, isto é, a posição dos furos abertos 1 - 9 e 1 - 5 9 é a mais vantajosa em relação à todos abertos.

Material: Areia

Camada do solo: $44 \mathrm{~cm}$ sobre à parede superior do dreno Carga de água: $1 \mathrm{~cm}$

Posição dos furos: 1-2-1

Consideramos a Tabela 14 onde os tratamentos

A, B e C são agora:

$A \rightarrow$ parte superior

$B \rightarrow$ parte inferior

$C \rightarrow$ todos

Tabela 14 - Demonstrativo de vazões

\begin{tabular}{cccccc}
\hline A & 42,00 & 43,02 & 39,63 & 23,34 & 147,99 \\
B & 56,81 & 50,13 & 42,57 & 36,64 & 186,15 \\
C & 53,63 & 48,53 & 40,10 & 32,49 & 174,75 \\
Totais & 152,44 & 141,68 & 122,30 & 92,47 & 508,89 \\
\hline Média & 50,81 & 47,23 & 40,77 & 30,82 & - \\
\hline
\end{tabular}


A análise é dada por:

Tabela 15 - Análise de variância

\begin{tabular}{llccc}
\hline \multicolumn{1}{c}{ CV } & GL & SQ & QM & F \\
\hline Blocos & 03 & 692,30 & 230,77 & 25,11 \\
Tratamento & 02 & 191,85 & 95,93 & 10,43 \\
Residuo & 06 & 55,14 & 9,19 & - \\
\hline TOTAL & 11 & 939,29 & - & - \\
\hline
\end{tabular}

$C=21.580,75$

$F_{3 ; 06 ; 0,05}=4,76 \quad F_{2 ; 06 ; 0,05}=5,14$

$F_{3 ; 06 ; 0,01}=9,78 \quad F_{2 ; 06 ; 0,01}=10,92$

Notamos, novamente aqui, uma diferença altamen te significativa quanto às condições de abertura dos furos, sendo que, os tratamentos também apresentam diferenças.

Aplicando-se o teste de Tukey a 5\%, teremos as seguintes comparações entre as médias:

$$
\begin{aligned}
& \overline{\mathrm{M}}=50,81 \\
& \overline{\mathrm{N}}=47,23 \\
& \overline{\mathrm{Z}}=40,77 \\
& \overline{\mathrm{K}}=30,82 \\
& \Delta=q^{-\mathrm{s} / \sqrt{r}}=4,90 \cdot \frac{3,03}{3} \\
& \Delta=8,57 \mathrm{dms}
\end{aligned}
$$


Tabela 16 - Comparação de médias

\begin{tabular}{ccccc}
\hline & $\overline{\mathrm{M}}$ & $\overline{\mathrm{N}}$ & $\overline{\mathrm{Z}}$ & $\overline{\mathrm{K}}$ \\
\hline$\overline{\mathrm{M}}$ & - & 3,58 & 10,04 & 19,99 \\
$\overline{\mathrm{N}}$ & - & - & 6,46 & 16,41 \\
$\overline{\mathrm{Z}}$ & - & - & - & 9,95 \\
$\overline{\mathrm{K}}$ & - & - & - & - \\
\hline
\end{tabular}

A $1 \%$, teremos:

$=7,03 \cdot \frac{3,03}{\sqrt{3}}$

$=12,29$ d.m.s.

Notamos, ainda que a condição I é a mais vantajosa.

Consideremos os segintes desdobramentos dos tratamentos $\mathrm{A}, \mathrm{B}$ e C:

B $\mathrm{x}$ Demais e C $\mathrm{x}$ A

B $\rightarrow 186,15$

Demais $\rightarrow 322,74$

$\mathrm{SQ}(\mathrm{B} \times$ Demais $)=1 / 4(186,15)^{2}+1 / 8(233,74)^{2}-(508,89)^{2}=$ $=102,34$

$C \rightarrow 174,75$

$A+147,99$

$\mathrm{SQ}(\mathrm{C} \times \mathrm{A})=1 / 4(174,75)^{2}+(1 / 4)(147,99)^{2}-(322,74)^{2}=89,51$ 
Tabela 17 - Análise de variância

\begin{tabular}{lcccc}
\hline B x Demais & 01 & 102,34 & 102,34 & 11,13 \\
C.x A & 01 & 89,51 & 89,51 & 9,74 \\
Tratamento & $(02)$ & $(191,85)$ & 95,93 & - \\
Blocos & 03 & 692,30 & 230,77 & - \\
Residuo & 06 & 55,14 & 9,19 & - \\
\hline TOTAL & 11 & - & - & - \\
\hline
\end{tabular}

$$
\begin{aligned}
& F_{1 ; 06 ; 0,05}=5,99 \\
& F_{1 ; 06 ; 0,01}=13,75
\end{aligned}
$$

Vemos que o tratamento B supera os demais, isto é, trabalhando-se com ele e fechando-se os demais, ocorre uma maior vazão/furo jā o tratamemto C supera o Tratamento A.

Material: Areia

Camada do solo: $28 \mathrm{~cm}$ sobre a parede superior do dreno Carga de água: $1 \mathrm{~cm}$ Posição de furos: 2-2

Consideramos a Tabeia 18 , onde os tratamentos A, B e C, sằo agora: 

$A \rightarrow$ parte inferior
$B \rightarrow$ parte superior
C $\rightarrow$ todos

Tabela 18 - Demonstrativo de vazões

\begin{tabular}{rrrrrr}
\hline & $\mathrm{M}$ & $\mathrm{N}$ & $\mathrm{Z}$ & $\mathrm{K}$ & TOTAIS \\
\hline A & 37,42 & 35,99 & 31,98 & 24,62 & 130,01 \\
B & 57,05 & 50,25 & 40,27 & 28,72 & 176,29 \\
$\mathrm{C}$ & 42,99 & 36,40 & 28,64 & 22,53 & 130,56 \\
\hline TOTAL & 137,46 & 122,64 & 100,89 & 75,87 & 436,86 \\
\hline MEDIA & 45,82 & 40,88 & 33,63 & 25,29 & - \\
\hline
\end{tabular}

A análise é dada por:

Pabela 19 - Análise de variāncia

\begin{tabular}{lcccc}
\hline \multicolumn{1}{c}{ CV } & GL & SQ & QM & F \\
\hline Blocos & 03 & 719,74 & 239,91 & 19,13 \$\$ \\
Tratamento & 02 & 352,79 & 176,39 & $14,06 \$ \$$ \\
Residuo & 06 & 75,21 & 12,54 & - \\
\hline TOTAL & 11 & $1.147,74$ & - & - \\
\hline
\end{tabular}

$C=15.903,88$
$F_{3 ; 6 ; 0,05}=7,76$
$\mathrm{F}_{2 ; 6 ; 0,05}=5,14$
$F_{3 ; 6 ; 0,01}=9,78$
$F_{2 ; 6 ; 0,01}=10,92$ 
Tanto os tratamentos quanto as posições de abertura dos furos, apresentam diferenças altamente significativas.

$$
\begin{aligned}
& \text { Aplicando-se Tukey a } 5 \% \text { teremos: } \\
& \Delta=\mathrm{q}^{\text {s/ }} \mathrm{r}=4,90-\frac{\sqrt{12,54}}{\sqrt{3}}=10,02 \\
& \overline{\mathrm{M}}=45,82 \\
& \overline{\mathrm{N}}=40,88 \\
& \overline{\mathrm{Z}}=33,63 \\
& \overline{\mathrm{K}}=25,29
\end{aligned}
$$

Tabela 20 - comparação entre às médias

\begin{tabular}{ccccc}
\hline & $\overline{\mathrm{M}}$ & $\overline{\mathrm{N}}$ & $\overline{\mathrm{Z}}$ & $\overline{\mathrm{K}}$ \\
\hline$\overline{\mathrm{M}}$ & - & 4,94 & 12,19 & 20,53 \\
$\overline{\mathrm{N}}$ & - & - & 7,25 & 15,59 \\
$\overline{\mathrm{Z}}$ & - & - & - & 8,34 \\
$\overline{\mathrm{K}}$ & - & - & - & - \\
\hline
\end{tabular}

A $1 \%$, teremos $\Delta=14,37$

Vemos que a condição $M$ supera a $Z$ e a $K$, sendo que a $\mathrm{N}$ supera somente a $\mathrm{K}$.

\section{Consideramos os seguintes desdobramentos:}

B $\times$ Demais

A $\times$ C

B $\quad \rightarrow 176,29$

Demais $\rightarrow 260,57$ 


$$
\begin{aligned}
\mathrm{SQ}(\mathrm{B} \times \text { Demais }) & =1 / 4(176,29)^{2}+1 / 8(260,57)^{2}-1 / 12(436,86)^{2}= \\
& =352,75
\end{aligned}
$$

$A+130,01$

$B \rightarrow 130,56$

SQ $(A \times C)=1 / 4(130,01)^{2}+1 / \$(130,56)^{2}-1 / 8(260,57)^{2}=0,038$

Tabela 21 - Análise de variância

\begin{tabular}{lcrcc}
\hline & & & & \\
\hline B x Dem. & 01 & 352,75 & 352,75 & $28,12 \$ \$$ \\
A X C & 01 & 0,038 & 0,038 & - \\
Tratamento & $(02)$ & $(352,79)$ & - & - \\
Blocos & 03 & 719,74 & - & - \\
Residuo & 06 & 75,21 & 12,54 & - \\
\hline TOTAL & 11 & $1.147,74$ & - & - \\
\hline
\end{tabular}

o tratamento B supera os demais, isto é, manten do-se a parte superior fechada e trabaihando-se com as inferiores obtêm-se um melhor resultado, utilizando-se tamebém a condição $M$.

Material: Areia

Camada do solo: $67 \mathrm{~cm}$ sobre a parede superior do dreno Carga de água: $1 \mathrm{~cm}$

Posição de furos: 2-2 
Consideramos a Tabela 22 onde:
$A \rightarrow$ superior
$B \rightarrow$ inferior
$\mathrm{C}+$ todos

Tabela 22 - Demonstrativo de vazões

\begin{tabular}{cccccc}
\hline & $\mathrm{M}$ & $\mathrm{N}$ & $\mathrm{Z}$ & $\mathrm{K}$ & TOTAIS \\
\hline $\mathrm{A}$ & 37,04 & 33,97 & 29,89 & 23,41 & 124,31 \\
$\mathrm{~B}$ & 38,75 & 35,79 & 31,75 & 25,95 & 132,24 \\
$\mathrm{C}$ & 35,78 & 31,47 & 26,06 & 21,01 & 114,32 \\
\hline TOTAIS & 111,57 & 101,23 & 87,70 & 70,37 & 370,87 \\
\hline Média & 37,19 & 33,74 & 29,23 & 23,46 & \\
\hline C $=11.462,04$ & & & &
\end{tabular}

Tabela 23 - análise de variância

\begin{tabular}{lcccc}
\hline Blocos & 03 & 317,49 & 105,83 & $247,26 \$ \$$ \\
Tratamento & 02 & 40,32 & 20,16 & $47,10 \$ \$$ \\
Residuo & 06 & 2,57 & 0,428 & - \\
\hline TOTAL & 11 & 360,38 & - & - \\
\hline
\end{tabular}

Tanto os tramentos, quanto as posições de abertura dos furos apresentam diferenças altamente "significativas. 


\section{Aplicando-se Tukey a 5\%, teremos:}

$$
\Delta=q^{s} / \sqrt{r}=4,90 \cdot \frac{\sqrt{0,428}}{\sqrt{3}}=1,85
$$

a 18, teremos:

$$
\begin{aligned}
& \Delta=7,03 \cdot \frac{\sqrt{0,428}}{\sqrt{3}}=2,66 \\
& \bar{M}=37,19 \\
& \bar{N}=33,74 \\
& \bar{Z}=29,23 \\
& \bar{K}=23,46
\end{aligned}
$$

Tabela 24 - Comparativo entre às médias

\begin{tabular}{ccccc}
\hline & $\overline{\mathrm{M}}$ & $\overline{\mathrm{N}}$ & $\overline{\mathrm{Z}}$ & $\overline{\mathrm{K}}$ \\
\hline$\overline{\mathrm{M}}$ & - & 3,45 & 7,96 & 13,73 \\
$\overline{\mathrm{N}}$ & - & - & 4,51 & 10,28 \\
$\overline{\mathrm{Z}}$ & - & - & - & 5,77 \\
$\overline{\mathrm{K}}$ & - & - & - & - \\
\hline
\end{tabular}

A condição M difere de todas as demais.' Consideremos os contrastes:

B $\mathbf{x}$ Demais
$A \times C$
B $-132,24$
Demais - 238,63 
$\mathrm{SQ}(\mathrm{B} \times$ Demais $)=1 / 4(132,24)^{2}+1 / 8(238,63)^{2}-1 / 12(370,87)^{2}=$ $=27,85$
$A \rightarrow 124,31$
$C+114,32$

$\left.S Q(A \times C)=1 / 4[124,31)^{2}+(114,32)^{2}\right]-1 / 8(238,63)^{2}=12,47$

Tabela 25 - Análise de variância

\begin{tabular}{lcrrc}
\hline & GL & SQ & QM & F \\
\hline B x Demais & 01 & 27,85 & 27,85 & 65,07 \\
A X C & 01 & 12,47 & 12,47 & 29,13 \\
\hline Tratamento & $102)$ & 40,32 & & \\
Bloco & 03 & 317,49 & & \\
Residuo & 06 & 2,57 & & \\
TOTAL & 11 & & & \\
\hline
\end{tabular}

Verificamos que o tratamento $B$ difere significa tivamente dos demais e que o A supera o $\mathrm{C}$. 
Material: Latosol vermelho amarelo

Camada do solo: $29 \mathrm{~cm}$ sobre a parede superior do dreno

Carga $\mathrm{H}_{2} \mathrm{O}: 1 \mathrm{~cm}$

Posição dos furos: 1-2-1

Consideramos a Tabela 26 onde:

T - Todos

L - Lateral

I - Inferior

S - Superior

Tabela 26 - Demonstrativo de vazões

\begin{tabular}{cccccc}
\hline & $\mathrm{M}$ & $\mathrm{N}$ & $\mathrm{Z}$ & $\mathrm{K}$ & TOTAIS \\
\hline $\mathrm{T}$ & 2,03 & 2,03 & 1,73 & 1,71 & 7,50 \\
$\mathrm{I}$ & 1,64 & 2,31 & 2,15 & 1,93 & 8,03 \\
$\mathrm{I}$ & 2,76 & 2,19 & 2,02 & 2,05 & 9,02 \\
$\mathrm{~S}$ & 2,89 & 2,65 & 2,28 & 1,98 & 9,80 \\
\hline \multirow{2}{*}{ TOTAIS } & 9,32 & 9,18 & 8,18 & 7,67 & 34,35 \\
\hline MEDIA & 2,33 & 2,29 & 2,05 & 1,92 & - \\
\hline
\end{tabular}

$C=73,75$ 
Tabela 27 - Análise de variância

\begin{tabular}{lllll}
\hline CV & GL & SQ & QM & F \\
\hline Blocos & 03 & 0,47 & 0,16 & 2,00 \\
Tratamento & 03 & 0,78 & 0,26 & 3,28 \\
Residuo & 09 & 0,73 & 0,08 & - \\
\hline TOTAL & 15 & 1,98 & - & - \\
\hline
\end{tabular}

Não houve diferença significativa entre os blocos e nem entre os tratamentos, isto é, as diferenças observa das são casuais.

$$
\begin{aligned}
& \text { Não hã vantagem em nenhum processo. } \\
& \mathrm{F}_{3 ; 9 ; 0,05}=3, \overline{86} \\
& \mathrm{~F}_{3 ; 9 ; 0,01}=6,99
\end{aligned}
$$


Material: Látosolo Vermelho amarelo

Camada do solo: $29 \mathrm{~cm}$ sobre a parede superior do dreno Carga $\mathrm{H}_{2} \mathrm{O}: 20 \mathrm{~cm}$

Posição dos furos: 1-2-1

Considerando a Tabela 28 onde

S - Superior

I - Inferior

T - Todos

Tabela 28 - Demonstrativo de vazões

\begin{tabular}{cccccc}
\hline & $\mathrm{M}$ & $\mathrm{N}$ & $\mathrm{Z}$ & $\mathrm{K}$ & TOTAIS \\
\hline $\mathrm{S}$ & 4,41 & 4,08 & 2,48 & 2,96 & 13,93 \\
$\mathrm{I}$ & 3,85 & 3,18 & 3,81 & 3,15 & 13,99 \\
$\mathrm{~T}$ & 3,48 & 3,28 & 3,20 & 2,99 & 12,95 \\
\hline TOTAIS & 11,74 & 10,54 & 9,49 & 9,10 & 40,87 \\
\hline MEDIA & 3,91 & 3,51 & 3,16 & 3,03 & - \\
\hline
\end{tabular}

$\mathrm{C}=139,19$ 
Tabela 29 - Análise de variância

\begin{tabular}{lllll}
\hline CV & GL & SQ & QM & F \\
\hline Blocos & 03 & 1,40 & 0,47 & 1,68 \\
Tratamento & 02 & 0,18 & 0,09 & 0,32 \\
Resíduo & 06 & 1,66 & 0,28 & - \\
\hline TOTAL & 11 & 3,24 & - & - \\
\hline
\end{tabular}

$$
\begin{array}{ll}
F_{3 ; 6 ; 0,05}=4,76 & F_{2 ; 6 ; 0,05}=5,14 \\
F_{3 ; 6 ; 0,01}=9,78 & F_{2 ; 6 ; 0,01}=10,92
\end{array}
$$

Não há diferença ou vantagem em nenhum processo. 
Material: Latosol Vermelho amarelo

Camada do solo: $20 \mathrm{~cm}$ sobre a parede superior do dreno

Posição dos furos: 1-2-1

Carga: $\mathrm{H}_{2} \mathrm{O}: 37 \mathrm{~cm}$

Consideramos a Tabela 30 onde:

S - Superior

I - Inferior

T - Todos

Tabela 30 - Demonstrativo de vazões

\begin{tabular}{cccccc}
\hline & $\mathrm{M}$ & $\mathrm{N}$ & $\mathrm{Z}$ & $\mathrm{K}$ & TOTAIS \\
\hline $\mathrm{S}$ & 5,90 & 7,12 & 3,90 & 3,89 & 20,81 \\
$\mathrm{I}$ & 4,90 & 4,92 & 4,36 & 4,60 & 18,78 \\
T & 6,87 & 6,10 & 5,31 & 5,67 & 23,95 \\
\hline TOTAIS & 17,67 & 18,14 & 13,57 & 14,16 & 63,54 \\
\hline MEDIA & 5,89 & 6,05 & 4,52 & 4,72 & - \\
\hline
\end{tabular}

$\mathrm{C}=336,44$ 
Tabela 31 - Análise de variância

\begin{tabular}{lcccc}
\hline CV & GL & SQ & QM & F \\
\hline Blocos & 03 & 5,54 & 1,85 & 3,08 \\
Tratamento & 02 & 3,39 & 1,69 & 2,83 \\
Residuo & 06 & 3,61 & 0,60 & - \\
TOTAL & 11 & 12,54 & - & - \\
\hline$F_{3 ; 6 ; 0,05}=4,76$ & $F_{2 ; 6 ; 0,05}=$ & 5,14 & \\
$F_{3 ; 6 ; 0,01}=9,78$ & $F_{2 ; 6 ; 0,01}=10,92$
\end{tabular}

Não hã vantagem em nenhum processo: todos se equivalem. 
Material: Latosol Vermelho amarelo

Camada do solo: $60 \mathrm{~cm}$ sobre a parede superior do dreno

Carga $\mathrm{H}_{2} \mathrm{O}: 1 \mathrm{~cm}$

Posição dos furos: 1-2-1

Tratamentos:

$$
\begin{aligned}
& \text { S - Superior } \\
& \text { I - Inferior } \\
& \text { L - Lateral } \\
& \text { T - Todos }
\end{aligned}
$$

$$
\text { Considere-se a Tabela } 32
$$

Tabela 32 - Demonstrativo de vazões

\begin{tabular}{cccccc}
\hline & $\mathrm{M}$ & $\mathrm{N}$ & $\mathrm{Z}$ & $\mathrm{K}$ & TOTAI \\
\hline $\mathrm{S}$ & 4,74 & 3,80 & 2,97 & 2,63 & 14,14 \\
$\mathrm{I}$ & 3,44 & 3,43 & 2,81 & 2,52 & 12,00 \\
$\mathrm{I}$ & 5,41 & 4,53 & 3,79 & 2,98 & 16,71 \\
$\mathrm{~T}$ & 2,77 & 2,42 & 2,33 & 2,20 & 9,72 \\
\hline TOTAL & 16,16 & 14,18 & 11,90 & 10,33 & 52,57 \\
\hline MEDIA & 4,04 & 3,54 & 2,98 & 2,58 & - \\
\hline
\end{tabular}

$C=172,73$ 
Tabela 33 - Análise de variância

\begin{tabular}{lcccc}
\hline CV & GL & SQ & QM & F \\
\hline Blocos & 03 & 4,90 & 1,63 & $8,71 * *$ \\
Tratamento & 03 & 6,68 & 2,23 & $11,93 * *$ \\
Residuo & 09 & 1,68 & 0,187 & - \\
\hline TOTAL & 15 & 13,26 & - & - \\
\hline
\end{tabular}

$$
\begin{aligned}
& \mathrm{F}_{3 ; 9 ; 0 ; 05}=3,86 \\
& \mathrm{~F}_{3 ; 9 ; 0,01}=6,99
\end{aligned}
$$

Existe uma diferença altamente significativa tan to entre os blocos quanto entre os tratamentos.

Apliquemos os métodos de Tukey a $5 \%$ e a $1 \%$ entre as medidas dos blocos.

$$
\begin{aligned}
& \overline{\mathrm{M}}=4,04 \\
& \overline{\mathrm{N}}=3,54 \\
& \overline{\mathrm{Z}}=2,98 \\
& \overline{\mathrm{K}}=2,58 \\
& \Delta=q^{\mathrm{s} / \sqrt{\mathrm{I}}} \\
& \Delta=4,42 \frac{\sqrt{0,187}}{\sqrt{4}}=0,95 \text { (5\%) } \\
& \Delta=5,96 \frac{\sqrt{0,187}}{\sqrt{4}}=1,29 \text { (1\%) }
\end{aligned}
$$


Tabela 34 - Comparação entre às médias

\begin{tabular}{ccccc}
\hline & $\overline{\mathrm{M}}$ & $\overline{\mathrm{N}}$ & $\overline{\mathrm{Z}}$ & $\overline{\mathrm{K}}$ \\
\hline$\overline{\mathrm{M}}$ & - & 0,5 & 1,06 & 1,46 \\
$\overline{\mathrm{N}}$ & - & - & 0,56 & 0,96 \\
$\overline{\mathrm{Z}}$ & - & - & - & 0,40 \\
$\overline{\mathrm{K}}$ & - & - & - & - \\
\hline
\end{tabular}

Verificamos que a condição (1-9) difere signifi cativamente da $\mathrm{z}$ e da $\mathrm{K}$, isto é, apresenta uma maior vazão por furo.

Consideramos os desdobramentos dos tratamentos:

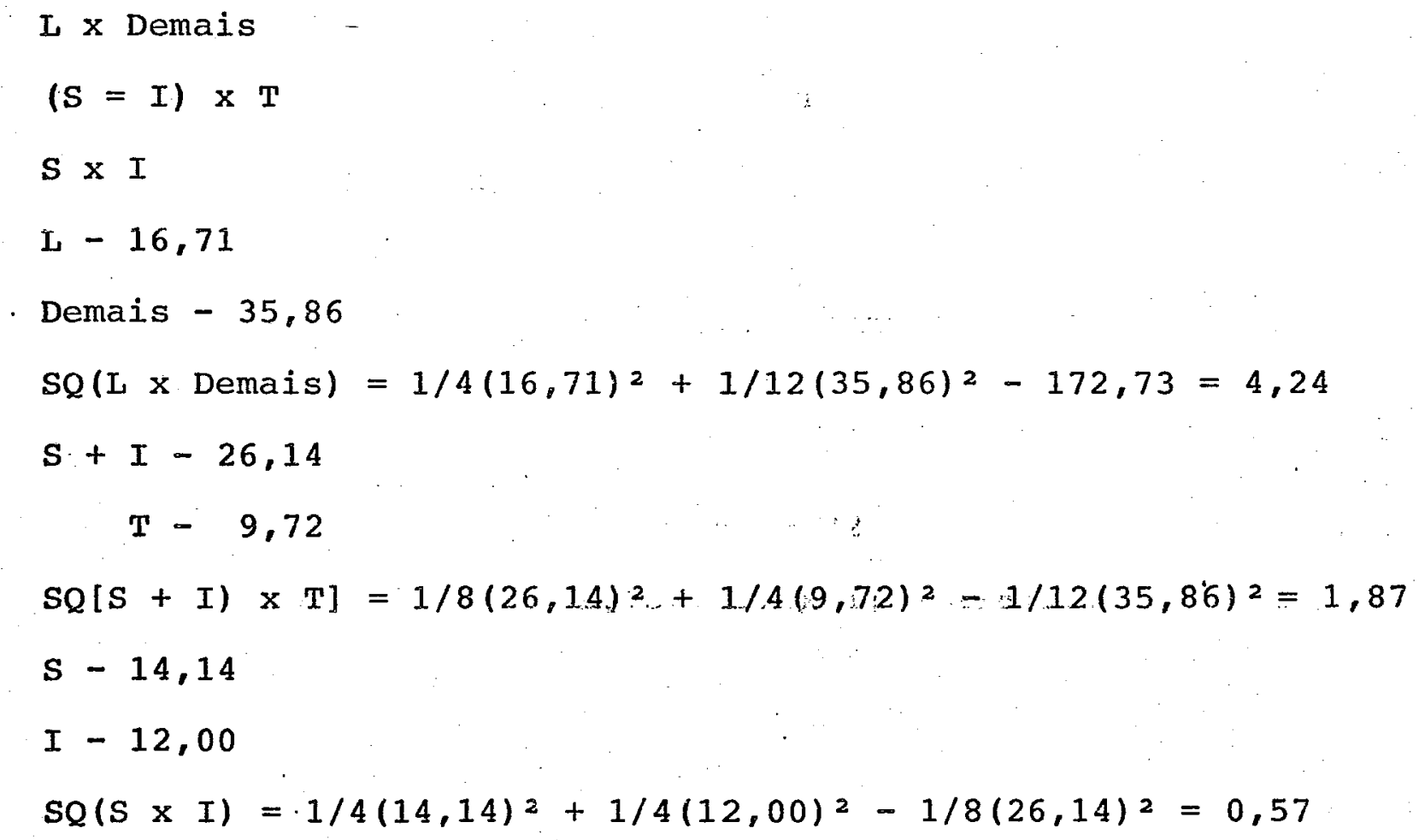


Tabela 35 - Análise de variância

\begin{tabular}{lcccc}
\hline & GL & SQ & QM & F \\
\hline L X Demais & 01 & 4,24 & 4,24 & 22,67 \\
(S + I) X T & 01 & 1,87 & 1,87 & 10,00 \\
S X I & 01 & 0,57 & 0,57 & 3,04 \\
\hline (Tratamento) & $(03)$ & $(6,68)$ & - & - \\
Blocos & 03 & 4,90 & - & - \\
Residuo & 09 & 1,68 & 0,187 & - \\
\hline ToTAL & 15 & - & - & \\
F $1 ; 9 ; 0,05$ & 5,12 & &
\end{tabular}


Material: Latosolo Vermelho amarelo

Camada do solo: $60 \mathrm{~cm}$ sobre a parede superior do dreno Posição dos furos: 1-2-1

Carga $\mathrm{H}_{2} \mathrm{O}: 6 \mathrm{~cm}$

Tratamentos: S - Superior

$$
\begin{aligned}
& \text { I - Inferior } \\
& \text { L - Laterais } \\
& \text { T - Totais }
\end{aligned}
$$

Considere-se a Tabela 36:

Tabela 36 - Demonstrativo de vazões:

\begin{tabular}{cccccc}
\hline & $\mathrm{M}$ & $\mathrm{N}$ & $\mathrm{Z}$ & $\mathrm{K}$ & $\mathrm{TOTAL}$ \\
\hline $\mathrm{S}$ & 2,90 & 2,53 & 2,40 & 2,55 & 10,38 \\
$\mathrm{I}$ & 2,69 & 2,39 & 1,89 & 2,10 & 9,07 \\
$\mathrm{~L}$ & 2,66 & 2,65 & 2,55 & 2,15 & 10,01 \\
$\mathrm{~T}$ & 2,26 & 2,43 & 2,39 & 2,33 & 9,41 \\
\hline TOTAL & 10,51 & 10,00 & 9,23 & 9,13 & 38,87 \\
\hline MEDIA & 2,63 & 2,50 & 2,31 & 2,28 & - \\
\hline
\end{tabular}


Tabela 37 - Análise de variância

\begin{tabular}{lcccc}
\hline & GL & SQ & QM & F \\
\hline Blocos & 03 & 0,32 & 0,10 & $2,5 \mathrm{m.s}$ \\
Tratamento & 03 & 0,26 & 0,08 & $2,0 \mathrm{m.s}$ \\
Residuo & 09 & 0,37 & 0,04 & - \\
TOTAL & 15 & 0,95 & - \\
F $_{3 ; 9 ; 0,05}=3,86$ & & \\
F $_{3 ; 9 ; 0,01}=6,99$ &
\end{tabular}


Material: Latosol Vermelho amarelo

Camada do solo: $49 \mathrm{~cm}$ sobre a parede superior do areno

Carga $\mathrm{H}_{2} \mathrm{O}: 1 \mathrm{~cm}$

Posição de furos: $1-2-1$

Tratamentos: S - Superior

$$
\begin{aligned}
& I \text { - Inferior } \\
& T \text { - Todos }
\end{aligned}
$$

Considere-se a Tabela 38

Tabela 38 - Demonstrativo de vazões

\begin{tabular}{cccccc}
\hline & $\mathrm{M}$ & $\mathrm{N}$ & $\mathrm{Z}$ & $\mathrm{K}$ & TOTAL \\
\hline $\mathrm{S}$ & 1,72 & 1,79 & $1,76,72$ & 1,83 & 7,10 \\
$\mathrm{I}$ & 2,75 & 2,02 & 1,96 & 1,87 & 8,60 \\
$\mathrm{~T}$ & 2,12 & 1,96 & 1,83 & 1,68 & 7,59 \\
\hline TOTAL & 6,59 & 5,77 & 5,55 & 5,38 & 23,29 \\
\hline MEDIA & 2,19 & 1,92 & 1,85 & 1,79 & - \\
\hline
\end{tabular}

$C=45,20$ 
Tabela 39 - análise de variância

\begin{tabular}{lcccc}
\hline & GL & SQ & QM & F \\
\hline Blocos & 03 & 0,28 & 0,09 & $1,8 \mathrm{m.s}$ \\
Tratamento & 02 & 0,29 & 0,14 & $2,8 \mathrm{m.s}$ \\
Residuo & 06 & 0,32 & 0,05 & - \\
\hline TOTAL & 11 & 0,89 & - & - \\
\hline
\end{tabular}

$$
\begin{aligned}
& F_{3 ; 6 ; 0,05}=4,76 \\
& F_{3 ; 6 ; 0,01}=9,78 \\
& F_{2 ; 6 ; 0,05}=5,14 \\
& F_{2 ; 6 ; 0,01}=10,92
\end{aligned}
$$

Não há diferença tanto entre blocos quanto entre tratamentos. 
Material: Latosol Vermelho amarelo

Camada do solo: $49 \mathrm{~cm}$ sobre a parede superior do dreno

Carga $\mathrm{H}_{2} \mathrm{O}: 17 \mathrm{~cm}$

Posição dos furos: 1-2-1

Tratamentos:

s - superior

I - Inferior

$\mathbf{T}$ - Todos

Consideremos a Tabela 40

Tabela 40 - Demonstrativo de vazões

\begin{tabular}{cccccc}
\hline & M & $\mathrm{N}$ & $\mathrm{Z}$ & $\mathrm{K}$ & TOTAL \\
\hline $\mathrm{S}$ & 2,14 & 3,38 & 2,34 & 2,53 & 9,39 \\
$\mathrm{I}$ & 2,61 & 2,71 & 2,16 & 2,28 & 9,76 \\
$\mathrm{~T}$ & 1,44 & 2,83 & 2,67 & 2,48 & 9,42 \\
\hline TOTAL & 6,19 & 7,92 & 7,17 & 7,29 & 28,57 \\
\hline MEDIA & 2,06 & 2,64 & 2,39 & 2,43 & - \\
\hline
\end{tabular}

$C=68,02$ 
Tabela 41 - Análise de variāncia

\begin{tabular}{llllll}
\hline CV & GL & SQ & QM & I \\
\hline Blocos & 03 & 0,51 & 0,17 & 1,07 \\
Tratamento & 02 & 0,02 & 0,01 & 0,06 \\
Residuo & 06 & 0,95 & 0,158 & - \\
\hline TOTAL & 11 & 1,48 & - & - \\
\hline
\end{tabular}

$$
\begin{aligned}
& F_{3 ; 6 ; 0,05}=4,76 \\
& F_{2 ; 6 ; 0,05}=5,14
\end{aligned}
$$

Não há diferença em nenhum dos métodos. 


\section{CONCLUSOẼS}

Os resultados do presente trabalho permitiram deduzir as seguintes conclusões:

a. A relação entre o número de orifícios de 1/2" e a vazão to tal foi linear para 184 orifíciosi Iocalizados por metro do dreno sendo este um de PVC rígido de $4 "$ e recoberto com en velope sintético na forma de manta de poliéster. Entretanto, apesar deste alto número de furos a vazão total foi sempre crescente sem atingir um patamar, nem houve qualquer fator aparente que a limitasse. Assim pode-se prever que, entre outros, os fatores que condicionarão a vazão to tal serão as propriedades físicas do solo, como sua permea bilidade.

b. Comparando-se um solo Latosol com Areia, ambos saturados e com uma lâmina de água na superfície observou-se, entre oụ tros, um contraste acentuado na vazão unitária dos orifícios. Assim, o dreno implantado com uma camada de latossolo de $28 \mathrm{~cm}$ acima da sua borda superior, com 36 furos, 
produziu uma descarga por furo aberto que foi de apenas 7,58 da vazão obtida nas mesmas condições, usando-se areia. Ainda, quando a camada de lotossolo foi de $67 \mathrm{~cm}$, a vazão por orifício aberto foi de $5,6 \%$ da vazão obtida com areia nas mesmas condições.

c. Somente no lotossolo é que se conseguiu atingir uma estabị lização na descarga por orifício, o que não ocorreu com a areia. Isto foi observado em duas situações. Na primeira com $29 \mathrm{~cm}$ de solo sobre o dreno, mantendo uma lâmina de água de $20 \mathrm{~cm}$ acima do mesmo a partir de 56 orificios abe $\underline{\underline{r}}$ tos. Na segunda foi conseguido a partir de 40 orifícios, abertos, com camada de solo de $2.9 \mathrm{~cm}$ e lâmina de $37 \mathrm{~cm}$.

d. Medindo-se a vazão total produzida: por grupo de 9 furos de. uma linha, e separadamente, a sua somatória foi superior ao total medido quando 36 orifícios em 4 linhas foram aber tos simultaneamente.

e. Na seç̧ão Transversal, a posição dos orificios, superior (S) Lateral (L) e inferior (I), mostrou-se capza de causar diferentes descargas individuais em virtude da carga hidráulica crescente nos respectivos orifícios S, L, I. Assim foi comprovado com o dreno instalado em água, sem solo. Também, na areia e no solo, a vazão cresceu com a posição dos orificios de $\mathbf{S}$ para I em virtude da maior carga hidráu lica, porém o efeito simultâneo da permeabilidade do material também foi relevante. Assim verificou-se que com .. a 
mesma lãmina de água a diferença entre as vazões S e I aumentou no material de maior permeabilidade.

f. Em virtude das conclusões anteriores que enfatizaram a vazão total é a vazão por orifício, a posição dos orifícios na secção transversal, os efeitos da carga hidráulica, da empresa e da permeabilidade do solo na vazão do dreno, não se conseguiu atingir um limite superior de dreno ou $233 \mathrm{~cm}^{2}$ de abertura total. Isto sugere que novos trabalhos sejam feitos aumentando a densidade de orifícios no dreno o que é sempre desejável, mesmo para solos de permeabilidade mais elevada como a areia, visto que por maior que seja a perfuração do dreno sempre haverá uma resistência à entrada da água no mesmo. 


\section{REFERÊNCIAS BIBLIOGRÁFICAS}

BRAVO, N.J., and G.O. SCHWAB, 1975. Effect of openings on inflow into corrugated drains. American Soviety of Agricultural Engineers. Paper no 75-2525.

CRUCIANI, D.E.; BOTREL, T.A. 1986.. Solução da equação de Kraijenhoff Van de Leur para previsão da elevação māxima do nível freático em problemas de drenagem subterrânea. Re vista ITEM, Associação Brasileira de Irrigação e Drenagem.

CRUCIANI, D.E. 1986. A Drenagem na Agricultura 4 á Edição Li vraria Nobel S.A. Parte II 6: 146-155; Parte III e IV: 185 317.

DE BOER, D.W.; JOHNSON, H.P. (1965). Agricultural Engineering $8: 494-498$. 
DENNIS, C.W.; TRAFFORD, B .D. 1975. The effect of permeable surrounds on the performance of clay field Drainage Pipes Journal of Hidrology, 24: 239-249.

GULATI, O.P; SCHWAB, G.O.; REEVE, R.C. 1970. Control of sediment flow into subsurface drains: Journal of the irrigation and drainage division - ASCE.IR4. 96: 437-449.

JONES, B.A. JR. (1960). Effect of crack width at tile joints on soil movement into draintile. Transactions, ASAE, $3: 33$ 51 .

KIRKHAM, D. and G.O. SCHWAB. 1951. The effect of Circular' Perforations on flow into Subsurface Drain Tubes. Agricultural Engineering: Part. I。 Theory April 211-214, Part II. Experiments and results. May: 270-274.

KIRKHAM, D. (1950). Potencial flow into circumferential openings in drain tubes. Physics Journal, 21: 655-660.

LUTHIN, J.N. 1967. Drenaje de Tierras Agrícolas - Editorial Limusa Wiley, S.A. Cap. 2: 101-137.

LUTHIN, J.N.; TAYLOR, G.S.; PRIETO, C. (1968) • Exit. gradients into subsurface drains. Hilgardia, 39: 419-428. 
LUTHIN, J.N. and A. HAIG. 1972. Some factors affecting flow into drainpipes, Hilgaldia, $41(10):$ 234-245.

LUTHIN, J.N. (1973). drainage Engineering. KRIEGER, Publ. Co. HUNTINGTON, New York. $250 \mathrm{p}$.

LUTHIN; TAYLOR; PRIETRO. 1972. Exit gradients into subsurface drains Hilgardia, $39(15): 419-428$.

MILLAR, A.A. 1978. Drenagem de Terras Agrícolas. Editora Mㅡ Graw-Hill do Brasil Ltda. Cap. 183-207.

SCHWAB, G.O. (1955). Plastic tubing for subsurface drainage. Agr. Eng. 36: 86-89.

SCHWAB, G.O.; D.W. DEBOER and H.P. JOHNSON, 1969. Effect of openings on design of subsurface drains. Journal of the Irrigation and Drainage Division: 199-209.

SCHWAB, G.O. 1969. Plastic tubing for subsurface drainage. Agr. Eng . $36(2): 86.89 .92$.

SKAGGS, R.W. 1978. Effect of drain tube openings on watertable drawdown. journal of the Irrigation and Drainage Division. ASCE. IRI, 13-21. 
SKAGGS, R.W.; TANG, Y.K. 1979. Effects of drain diameter, openings and envelopes on watertable drawdown. Transations of the ASAE. 326-333.

SOMMERFELDT, T.G. 1975. Outflow from various subsurface drainage materials. Transactions of the ASAE. 85-94.

WATTS, D.C.; LUTHIN, J.N. (1963). Tests of thick fiberglass filters for subsurface drains. Hilgardia, 35: 33-46.

WESSELING, J.; HOMMA, F. 1967. Entrance resistance of plastic drain tubes. Neth J. Agric. Sci. 15: 170-182.

YOUNGS, E.G. (1965). A comparison of the performance of some plastic and tile drains. J. Agr. Eng. Res. 10: 202203. 